\title{
Central venous catheter-related infections in hematology and oncology: 2020 updated guidelines on diagnosis, management, and prevention by the Infectious Diseases Working Party (AGIHO) of the German Society of Hematology and Medical Oncology (DGHO)
}

\author{
Boris Böll ${ }^{1}$ (D) Enrico Schalk ${ }^{2}$. Dieter Buchheidt ${ }^{3}$. Justin Hasenkamp ${ }^{4} \cdot$ Michael Kiehl $^{5} \cdot$ Til Ramon Kiderlen $^{6}$. \\ Matthias Kochanek ${ }^{1}$. Michael Koldehoff ${ }^{7}$. Philippe Kostrewa ${ }^{8}$. Annika Y. Claßen ${ }^{1}$. Sibylle C. Mellinghoff ${ }^{1}$. \\ Bernd Metzner $^{9}$ - Olaf Penack ${ }^{10}$ - Markus Ruhnke ${ }^{11}$ • Maria J. G. T. Vehreschild ${ }^{12}$ • Florian Weissinger $^{13}$. \\ Hans-Heinrich Wolf ${ }^{14}$. Meinolf Karthaus ${ }^{15}$. Marcus Hentrich ${ }^{16}$
}

Received: 11 August 2020 / Accepted: 23 September 2020 / Published online: 30 September 2020

(C) The Author(s) 2020

\begin{abstract}
Cancer patients frequently require central venous catheters for therapy and parenteral nutrition and are at high risk of central venous catheter-related infections (CRIs). Moreover, CRIs prolong hospitalization, cause an excess in resource utilization and treatment cost, often delay anti-cancer treatment, and are associated with a significant increase in mortality in cancer patients. We therefore summoned a panel of experts by the Infectious Diseases Working Party (AGIHO) of the German Society of Hematology and Medical Oncology (DGHO) and updated our previous guideline on CRIs in cancer patients. After conducting systematic literature searches on PubMed, Medline, and Cochrane databases, video- and meeting-based consensus discussions were held. In the presented guideline, we summarize recommendations on definition, diagnosis, management, and prevention of CRIs in cancer patients including the grading of strength of recommendations and the respective levels of evidence. This guideline supports clinicians and researchers alike in the evidence-based decision-making in the management of CRIs in cancer patients.
\end{abstract}

Meinolf Karthaus and Marcus Hentrich contributed equally to this work.

Boris Böll

boris.boell@uk-koeln.de

1 Department I of Internal Medicine, Hematology and Oncology, Intensive Care Medicine, Center for Integrated Oncology Aachen Bonn Cologne Duesseldorf, University of Cologne, Kerpener Strasse 62, 50937 Cologne, Germany

2 Department of Hematology and Oncology, Otto-von-Guericke University Magdeburg, Medical Center, Magdeburg, Germany

3 Department of Hematology and Oncology, Mannheim University Hospital, Heidelberg University, Mannheim, Germany

4 Clinic for Hematology and Oncology, University Medicine Göttingen, Georg-August-University, Göttingen, Germany

5 Department of Internal Medicine, Frankfurt (Oder) General Hospital, Frankfurt/Oder, Germany

6 Department of Hematology, Oncology and Palliative Care, Vivantes Clinic Neukoelln, Berlin, Germany

7 Department of Bone Marrow Transplantation, West German Cancer Center, University Hospital Essen, University of Duisburg-Essen, Essen, Germany
8 Department of Hematology and Oncology, Campus Fulda, Philipps-University Marburg, Fulda, Germany

9 Department of Hematology and Oncology, University Hospital Oldenburg, Oldenburg, Germany

10 Department of Hematology, Oncology, and Tumor Immunology, Charité - Universitätsmedizin Berlin, Berlin, Germany

11 Department of Hematology and Oncology, Helios Klinikum Aue, Aue, Germany

12 Department of Internal Medicine, Infectious Diseases, University Hospital Frankfurt, Goethe University Frankfurt, Frankfurt am Main, Germany

13 Department of Hematology, Oncology and Palliative Care, Department of Internal Medicine, Evangelisches Klinikum Bethel, Bielefeld, Germany

14 Department III of Internal Medicine, Hematology, Oncology and Hemostaseology, Südharzklinikum, Nordhausen, Germany

15 Department of Hematology, Oncology \& Palliative Care, Klinikum Neuperlach, Munich, Germany

16 Department of Hematology and Oncology, Red Cross Hospital Munich, Munich, Germany 
Keywords Central venous catheter $\cdot$ Catheter infection $\cdot$ CRBSI $\cdot$ CLABSI $\cdot$ Neutropenia $\cdot$ Cancer

\section{Introduction}

Cancer patients frequently require central venous catheters (CVCs) for cancer treatment, blood transfusion, and parenteral nutrition. However, cancer patients are at particular risk of infections including CVC-related infections (CRIs) due to disease- and treatment-related immunosuppression. According to current estimates, more than 5 million CVCs are inserted in the USA annually and similar rates have been reported for European countries [1-4]. The frequency of resulting central line-associated bloodstream infections (CLABSIs) in cancer patients is estimated at $0.5-10$ per 1000 CVC-days. The associated mortality ranges from 12 to $40 \%$ depending on several factors, including patient comorbidities, CVC type, and microorganism causing the infection [2, 5-8]. Importantly, up to $70 \%$ of all CRIs may be preventable with current evidence-based strategies [9]. Several institutions and public authorities have issued comprehensive guidelines on CRIs such as the German Commission for Control and Prevention of Infections (KRINKO). These recommendations and guidelines may include obligatory measures and have high normative value but are not specifically targeted at cancer patients. The guideline presented here is based on our previous guideline [10] that summarizes current data on epidemiology, diagnosis, treatment, and prevention of CRIs in cancer patients to guide clinicians and identify areas of uncertainty.

\section{Methods}

We assigned subtopics of this guideline to a panel of 20 experts in the field of internal medicine, hematology and oncology, infectious diseases, infection control and hospital epidemiology, and critical care medicine. We then conducted independent literature searches of the PubMed, Medline, and Cochrane databases using combinations of the following search terms: central venous catheter infection, central venous catheter-related bloodstream infection, central venous catheter-associated bloodstream infection, cancer, neutropenia, definition, pathogenesis, pathogens, epidemiology, incidence, risk factors, diagnosis, treatment, management, surveillance, education, and prevention. The consensus process was carried out in e-mail-, telephone-, video-, and meeting-based discussion groups. The strength of each recommendation and the grade of evidence were adapted to the criteria of the European Society for Clinical Microbiology and Infectious Diseases (ESCMID; Table 1) [11]. The presented guideline replaces our previous guideline [10] and was approved by the assembly of the members of the Infectious Diseases Working Party (AGIHO) of the German Society of Hematology and Medical Oncology (DGHO) on March 23, 2018, and again after updating the recommendations and references on May 7 , 2020, as a video conference. All authors approved the final version of the manuscript and the recommendations before submission.

\section{Results}

\section{Definitions}

Based on clinical symptoms and laboratory findings, localized infections of CVCs such as exit-site infections, tunnel infections, and port-pocket infections are distinguished from CLABSIs or catheter-related blood stream infections (CRBSI). However, the definitions of CLABSI or CRBSI are not interchangeable, as criteria vary substantially between the two definitions [1, 20]. Importantly, the Infectious Diseases Society of America (IDSA) definition of CRBSI and the US Centers for Disease Control and Prevention (CDC) definition of CLABSI do not specifically target cancer patients and lack specificity in this particular patient population [1, 20-27]. As the CDC definition of CLABSI was shown to overestimate the rate of CVC-derived bacteremia in cancer patients, the concept of mucosal barrier injury (MBI) laboratory-confirmed bloodstream infection (LCBI) was proposed [20]. This surveillance definition intends to identify a subset of bacteremia in cancer patients, which is likely to be related to mucosal barrier injury with bacterial translocation from the gastrointestinal tract and not related to infection of a CVC. However, the criteria for MBI-LCBI are restricted to specific subsets of cancer patients and specific microorganisms and might have limited applicability in clinical practice $[28,29]$. In this regard, a recent retrospective review of 250 patients in a Japanese academic hospital identified 44 patients during a 47-month period with CLABSI, of which about half (45.5\%) met the definition of MBI-LCBI and $24(54.5 \%)$ were classified as non-MBI-LCBI [30]. Similarly, Chaftari and colleagues reviewed 149 cases of CLABSI at their institution, of which 70 (47\%) had definite CRBSI. Even though CRBSI was more common in patients with non-MBI-LCBI, about one in five patients with MBI-LCBI (18\%) had definitive CRBSI [22]. Thus, the use of MBI-LCBI criteria in cancer patients might be useful for surveillance purposes, but might have limited applicability to everyday practice. We thus recommend against the use of CLABSI for the definition of CRIs in cancer patients (DII). To account for the specific 
Table 1 Categories of evidence levels used in this guideline

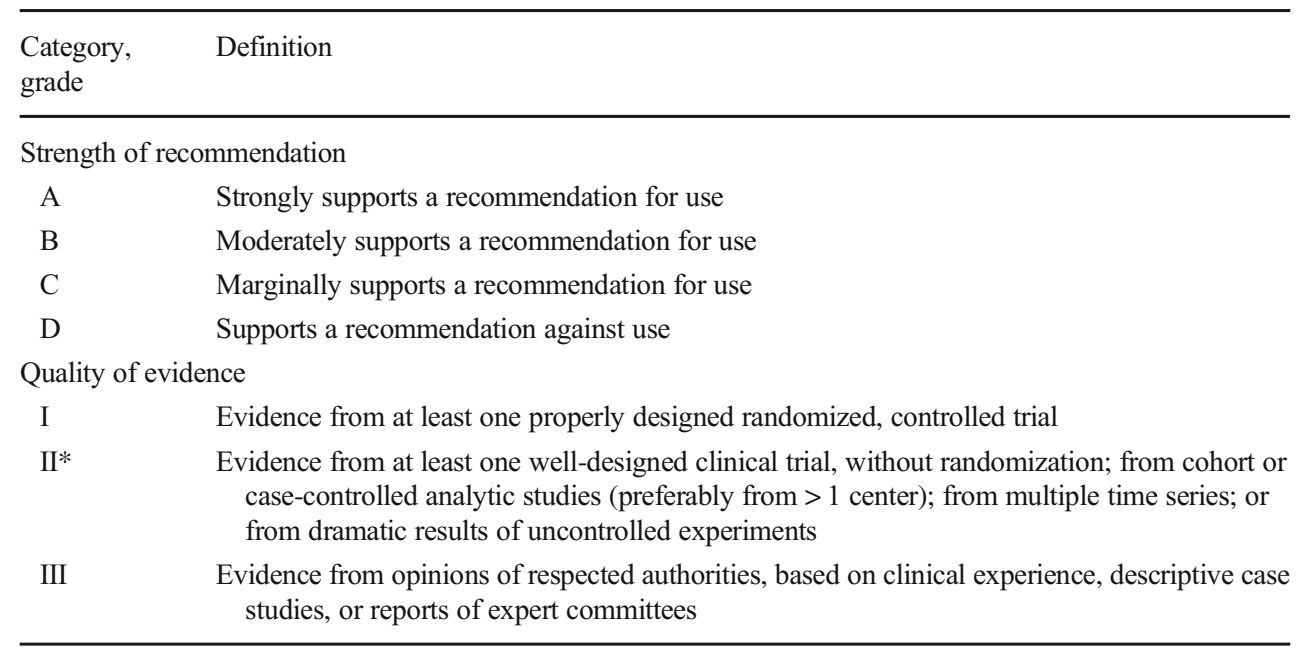

*Added index: r: Meta-analysis or systematic review of randomized controlled trials. t: Transferred evidence, that is, results from different patients' cohorts, or similar immune status situation. h: Comparator group is a historical control. u: Uncontrolled trial. a: Published abstract (presented at an international symposium or meeting) characteristics of cancer patients, we recommend the distinction between "definite," "probable," and "possible" CRBSIs as proposed in 2012 and outlined in Table 2 [10, 31-34] (AII).

\section{Pathogenesis and risk factors}

In short-dwelling catheters ( $<14$ days), colonization of CVCs via migration of skin microorganisms resulting in extraluminal spread of bacteria along the outer surface of the catheter predominates as pathomechanism of infection [35]. Within $24 \mathrm{~h}$ of CVC placement, the interior surface of the catheter may be covered with a biofilm embedding bacteria and fungi. Consequently, colonization and infection via catheter hubs and, less frequently, via infusion solutions resulting in intraluminal spread of microorganisms are more common in longer-dwelling CVCs ( $\geq 14$ days) $[1,35,36]$. Risk factors for catheter-related infections include a high level of skin colonization at the insertion site and the catheter hub as well as the administration of blood products and total parenteral nutrition [7, 21, 37, 38]. Unsurprisingly, patients requiring more than one CVC are at higher risk of CRI [39]. Among cancer patients, patients with hematological malignancies are at higher risk for CRIs compared with patients with solid tumors and the risk of infection is higher in patients with aggressive hematological malignancy such as leukemia and high-grade lymphoma, compared with patients with less aggressive malignancies [5, 40-42]. Neutropenia is a major independent risk factor for CRIs, and neutropenic patients with bloodstream infections are at higher risk of mortality compared with nonneutropenic patients [43-46]. Interestingly, neutropenia at the time of CVC insertion had no association with rates of definitive or probable CRBSI comparing matched neutropenic with non-neutropenic patients in a recent analysis of 806 patients [47]. Although patients undergoing allogeneic or autologous hematopoietic stem cell transplantation (HSCT) are commonly neutropenic, HSCT might further increase the risk of CLABSI and CRBSI independent of the impact of neutropenia. In a recent retrospective study by McDonald and colleagues on 352 patients undergoing allogeneic HSCT, the use of a matched unrelated donor (MUD) and/or haploidentical donor and the use of an ablative conditioning regimen were independently associated with development of CLABSI on multivariate analysis [48]. Thrombosis, even when detectable only by ultrasound screening, was shown to be a risk factor for CRIs, and infection of the catheter in turn promotes thrombosis [49-51]. Other risk factors include male gender, disease stage, age, and reduced performance status $[52,53]$. Of note, rates of CRI also depend on the devices used, and the risk of CRI differs between cuffed tunneled CVCs, subcutaneous implanted ports, peripherally inserted CVCs (PICCs), and percutaneous non-cuffed or tunneled CVCs [21]. Reported rates of CRIs in implantable and tunneled catheters are lower compared with rates in nontunneled catheters $[21,54,55]$. PICCs have become more common for patients requiring long-term venous access, and reported rates of CRIs in several studies and one recent metaanalysis suggest a lower or comparable risk of CRI compared with CVCs [56-63]. In addition, timing and procedure of CVC placement also might influence CRI rates, as catheter placement by interventional radiologists was reported to be associated with less complications including CRIs, than surgically placed catheters [64]).

\section{Epidemiology}

The incidence of CRI complications including CRBSI in cancer patients is highly dependent on the studied patient population, the setting, and the definitions used. As a consequence 
Table 2 Diagnostic criteria for CVC-related bloodstream infections (CRBSI)

\begin{tabular}{|c|c|c|}
\hline Diagnosis & Criteria (I) & Criteria (II) \\
\hline \multirow[t]{3}{*}{ Definite CRBSI } & $\begin{array}{l}\text { Growth of same pathogen from blood culture of } \\
\text { peripheral vein and from culture of CVC tip }\end{array}$ & $\begin{array}{l} \pm \text { in vitro susceptibility testing results in the same resistance } \\
\text { pattern }(\mathrm{AI})[12]\end{array}$ \\
\hline & \multirow[t]{2}{*}{$\begin{array}{l}\text { Growth of same pathogen from blood culture of CVC } \\
\text { and from blood culture of peripheral vein }\end{array}$} & $\begin{array}{l}\text { And DTTP } \geq 2 \mathrm{~h} \text { (AIIt) or, for quantitative blood cultures, } \\
\mathrm{a} \geq 3 \text {-fold greater colony count of pathogens grown from } \\
\text { blood culture of CVC than the colony count from a peripheral } \\
\text { vein (AIIt) }[1,12,13]\end{array}$ \\
\hline & & $\begin{array}{l}\text { DTTP }>2 \mathrm{~h} \text { is inaccurate to rule out CRBSI in patients with } \\
\text { detection of } S \text {. aureus }[14,15] \text { or Candida spp. [16-19] (DIIt) }\end{array}$ \\
\hline \multirow[t]{3}{*}{ Probable CRBSI } & \multirow[t]{3}{*}{$\begin{array}{l}\text { Growth of the same pathogen from blood culture of } \\
\text { CVC and from blood culture of peripheral vein }\end{array}$} & And no criteria for definitive CRBSI \\
\hline & & $\begin{array}{l}\text { And detection of coagulase-negative Staphylococcus spp., } \\
\text { S. aureus, or Candida spp. }\end{array}$ \\
\hline & & And exclusion of other infection sites (BIII) \\
\hline Exit-site infection & Clinical signs of infection $\leq 2 \mathrm{~cm}$ from the CVC exit & And BSI without criteria for definitive CRBSI (BIII) \\
\hline $\begin{array}{l}\text { Tunnel infection } \\
\text { (Hickman and Broviac } \\
\text { catheter) }\end{array}$ & $\begin{array}{l}\text { Clinical signs of infection }>2 \mathrm{~cm} \text { from } \mathrm{CVC} \text { exit site } \\
\text { along the subcutaneous part of CVC }\end{array}$ & And BSI without criteria for definitive CRBSI (BIII) \\
\hline $\begin{array}{l}\text { Pocket infection } \\
\text { (implanted port } \\
\text { system) }\end{array}$ & Clinical signs of infection of subcutaneous pocket & And BSI without criteria for definitive CRBSI (BIII) \\
\hline \multicolumn{3}{|l|}{ Possible CRBSI } \\
\hline \multirow[t]{4}{*}{ CVC colonization } & \multirow[t]{2}{*}{$\begin{array}{l}\text { Growth of pathogen from CVC tip (>15 CFU in } \\
\text { semiquantitative/> } 100 \mathrm{CFU} \text { in quantitative culture) }\end{array}$} & $\begin{array}{l}\text { And clinical or laboratory signs of infection (e.g., } \\
\text { leukocytosis or elevated C-reactive protein) }\end{array}$ \\
\hline & & And no BSI (BIII) \\
\hline & $\begin{array}{l}\text { Pathogen detected in blood culture that is typically } \\
\text { causing CRI (S. epidermidis, S. aureus, Candida } \\
\text { spp.) }\end{array}$ & And no other focus identified (BIII) \\
\hline & Remission of fever in $<48 \mathrm{~h}$ after $\mathrm{CVC}$ removal & And no other focus identified (BIII) \\
\hline
\end{tabular}

$C R B S I$, catheter-related bloodstream infection; $B S I$, bloodstream infection; $C F U$, colony forming unit; $C V C$, central venous catheter; $D T T P$, differential time to positivity of CVC blood culture and peripheral blood culture

of the high variability of the studies, the rate of CRIs in cancer patients reported in the literature varies between 9 and $80 \%$ [65]. A recent large retrospective study analyzed registry data (SEER-Medicare) of more than 35,000 adult cancer patients above the age of 65 years with long-term catheters (mainly port catheters) [53]. The authors reported an overall incidence of CRIs of $16-31 \%$ in patients with long-term CVCs and a two- to five-fold risk of CRIs compared with matched controls without CVC, suggesting an important impact of catheterization on the incidence of CRIs [53].

Surveillance and cohort studies in cancer patients report CRBSI/CLABSI rates of 1.05-14.4 per 1000 CVC-days [6, 41, 66-68]. A recent pooled analysis of 1194 cancer patients derived from the German SECRECY registry and a prospective randomized trial testing an antimicrobial dressing in neutropenic cancer patients (COAT-trial) used the definitions of definite CRBSI and definite plus probable CRBSI, reporting an incidence of 2.7 and 6.7 for definite CRBSI and definite plus probable CRBSI per 1000 catheter-days, respectively [32]. Using the less stringent CDC definition, a CLABSI rate of 2.9-6.3 per 1000 CVC-days was reported in a recent randomized controlled trial in adult cancer patients testing different skin disinfectant solutions (alcohol-based solutions with or without octenidine) [37, 69]. Higher rates were reported in studies focusing on neutropenic patients and patients receiving autologous or allogeneic hematopoietic stem cell transplantation, with CRBSI/CLABSI rates up to 24.3 per 1000 neutropenic days in one study [48, 70-72]. In a retrospective study on patients in an outpatient transplant unit at an academic tertiary center, the cumulative incidence of CLABSIs within 100 days after allogeneic stem cell transplantation (SCT) was $9 \%$, with the majority $(67 \%)$ occurring within the first 30 days after transplant [48]. The German ONKO-KISS surveillance registry reported CLABSI incidence of 4.6 and 3.4 per 1000 CVC-days in autologous and allogeneic HSCT recipients, respectively, in 2019. During neutropenia, these rates increased to 10.6 and 5.9 per 1000 CVC-days in patients after autologous and allogeneic HSCT, respectively [73].

\section{Pathogens}

The distribution of pathogens causing CRIs in cancer patients depends on the population studied and the definition of CRIs 
applied. Overall, coagulase-negative staphylococci (CoNS) are the most commonly detected bacteria in cancer patients with CLABSI, followed by other Gram-positive bacteria such as Staphylococcus aureus, Enterococci, and Streptococci [44, 74-77]. Accordingly, Schalk and colleagues recently reported a large multicenter cohort of 3000 cases of definitive and probable CRBSI in cancer patients from registry and trial data and found a similar distribution of pathogens as in smaller single-center studies with CoNS as the most common causative pathogens for CRBSIs [32]. The frequency of Gramnegative bacteria such as Escherichia coli, Pseudomonas aeruginosa, and Klebsiella spp. varies between studies within the range of $20-27 \%[28,44,74,75]$. Recent longitudinal studies suggest a shift from the predominance of Grampositive to Gram-negative bacteria causing CRBSI in cancer patients in more recent periods [77, 78]. A recent retrospective study compared two cohorts of cancer patients from 1999 to 2000 and 2013 to 2014, and found Gram-negative organisms as predominant etiologic bacteria in the latter period contributing to $41 \%$ of the CRBSI [79]. In addition, Gram-negative bacteria are more commonly found as microorganisms causing blood stream infections (BSI) in neutropenic patients, compared with non-neutropenic patients $[28,80]$. This is likely due to bacterial translocation of gut organisms frequently causing BSI rather than CRI in neutropenic patients [81]. Increasing rates of antibiotic resistance including multi-drug resistance (MDR) have been reported worldwide in the last decade also in studies focusing on cancer patients [82-84]. Therefore, local epidemiology and resistance patterns as well as known individual colonization with resistant pathogens should be considered factors for the choice of empiric antibiotic therapy in patients with CRBSI [45, 46].

Candida spp. have been reported in 2-13\% of patients with CRBSI [31, 44, 74], and polymicrobial cultures were reported in 11-30\%, with the incidence again depending on the definition of CRBSI used [31, 74, 85, 86]. Using the definition of definite CRBSI and probable CRBSI, CoNS, Gram-negative bacteria, and Candida spp. were reported in $73 \%, 15.5 \%$, and $1 \%$, respectively, in a recent multicenter study for both definite CRBSI and probable CRBSI combined in cancer patients [31]. Of note, the predominance of Gram-negative bacteria that had been described in other recent cohort studies using less cancer-specific definitions was not observed with the use of the definition of definite plus probable CRBSI [31, 32].

\section{Diagnosis}

Diagnostic procedures for the detection of CRIs should be initiated in patients with any type of CVC (conventional CVCs, PICCs, implantable CVCs, etc.) upon clinical signs and symptoms of infection and without any other apparent source of infection. Symptoms may include local signs such as erythema, swelling and pain or more frequently systemic signs such as fever and hypotension, or a combination of both. In all patients, a thorough physical examination should be performed, complemented by microbiological testing (blood cultures) and imaging according to current guidelines [45, 87].

\section{Diagnostic procedures for suspected CRBSI}

In patients with suspected CRBSI, at least two pairs of blood cultures with adequate quantity of blood $(\geq 10 \mathrm{ml}$ depending on the culture flask used) should be taken simultaneously, one pair from a peripheral vein and one pair from the CVC [1, 88-90]. Samples should be drawn before the administration of antibiotics and under sterile precautions to avoid contamination. Studies sampling all lumens in multi-lumen CVCs indicate that colonization might be detectable only in one of several lumens, and therefore, blood cultures from all lumens should be sampled [91-94]. However, the higher detection rate needs to be carefully balanced against the potential harm caused by the withdrawal of large blood volumes.

Quantitative or semiquantitative blood cultures taken simultaneously from the CVC and a peripheral vein with a colony count ratio of $3: 1$ to $10: 1$ of the same microorganism species are considered indicative of CRBSI [12, 36, 65]. However, the method of testing for quantitative blood cultures is time consuming, elaborate, and expensive, and the availability is therefore limited and not a clinical routine in most microbiological laboratories [65].

The differential time to positivity (DTTP), defined as $>2 \mathrm{~h}$ earlier positivity of CVC-drawn versus peripheral blood cultures detecting the same pathogen during automated incubation, has been reported as a sensitive and specific diagnostic marker for CRBSI in patients with short- and long-term CVCs $[95,96]$. The method was studied in intensive care unit (ICU) patients and cancer patients including neutropenic patients and recipients of allogeneic HSCT [65, 74, 95-97]. A DTTP $>2 \mathrm{~h}$ has been shown to be predictive for CRBSI with reported sensitivity and specificity ranging from 72 to $100 \%$ and a negative predictive value of $91-92 \%$ [74, 92, 95, 96]. DTTP was therefore proposed as a useful diagnostic tool particularly to prevent unnecessary CVC removal in patients with limited intravenous access options [65, 74]. Recent studies evaluating the 2-h cutoff DTTP for patients with candidemia [16-19] and $S$. aureus bacteremia $[14,15]$ showed insufficient test performance to diagnose or exclude CRBSI in patients with detection of these pathogens. Therefore, the use of DTTP in patients with candidemia and $S$. aureus bacteremia is not recommended for diagnosis or exclusion of CRBSI and as a decision tool for CVC preservation.

In patients without possibility of blood culturing because no blood can be aspirated via the catheter, sampling the internal catheter surface in situ by endoluminal brushing may be useful $[91,92]$. However, the technique is not widely available and might underestimate CRI in short-dwelling CVCs 
where external surface colonization plays an important role. Moreover, endoluminal brushing might carry the risk of inducing bacteremia in patients with colonized catheter and is not recommended for routine diagnostics.

If the catheter is removed in case of suspected CRI, the catheter tip should be cut to a length of $\sim 5 \mathrm{~cm}$ and placed in a sterile dry container for transport. Standard methods for microbiological diagnosis of CRI after CVC removal have previously been reviewed $[13,98]$.

\section{Diagnostic procedures for suspected localized CRI}

Local CRI as exit-site infections and tunnel infections should be suspected based on clinical signs and symptoms. Some authors recommend taking a swab for culture and staining in case of secretion at the exit site of the CVC $[1,88]$. Nonetheless, skin swabs do not allow for a reliable differentiation between colonizing and pathogenic organisms, even in case of purulent secretion at the exit site, and have limited validity in patients with suspected CRI [35, 88, 99]. In a recent study, cultures of skin swabs from the skin overlying reservoir ports and from the insertion site and hubs of tunneled catheters had low sensitivity and specificity (23-45\% and 60-63\%, respectively) for the prediction of CRBSI, defined as isolation of the same microorganism in both the colonized CVC and at least one peripheral blood culture obtained 1 week before or after catheter withdrawal [100]. Therefore, skin swabs have limited validity to confirm or rule out local CRI and are not recommended in clinical routine. Diagnostic procedures in case of suspected CRI are summarized in Fig. 1, and recommendations are summarized in Table 3.

\section{Prevention}

Recommendations for the prevention of CRI are summarized in Table 4.

\section{Education, bundles, and surveillance}

Avoiding unnecessary catheterization and prompt removal of no longer required $\mathrm{CVCs}$ are effective measures to reduce CRBSI, in particular in longer-dwelling catheters. Thus, institution-wide standards such as daily audits to assess whether each CVC is still needed are strongly encouraged. The use of bundles for the prevention of CRIs, including prospective consistent surveillance of CRI rates; education, instructions, and surveillance of hand hygiene; aseptic catheterization; and handling of CVCs, effectively reduces CRI rates and is recommended [101-107]. These bundles may also include recommendations on appropriate nursing staff levels and the designation of designated trained personnel for placement and handling of CVCs, as studies indicate an impact of both factors in lowering CRI rates [108, 109]. These bundles particularly stress the need for hand hygiene and disinfection
Table 3 Standard procedures in the diagnosis of CVC-related infections (CRI)

Before CVC removal

- Rule out other possible sources of infection by clinical examination and imaging procedures, if necessary.

- Inspect the CVC insertion site or pocket or tunnel for signs of local infection. Palpate the pocket or tunnel.

- Do not take skin swabs as they have limited validity to confirm or rule out local CRI in clinical routine (DIII).

- Take one pair of blood cultures (aerobic and anaerobic) from a peripheral vein and one from the CVC for microbiological evaluation (AIIt).

- In case of multi-lumen CVC, draw separate blood cultures from each lumen (BII).

- Determine the DTTP between the CVC and peripheral blood culture sample (for pathogens other than S. aureus or Candida spp.) (AIIt).

- Do not use DTTP in patients with candidemia and $S$. aureus bacteremia for diagnosis or exclusion of CRBSI and as a decision tool for CVC preservation (DIIt).

- Do not use endoluminal brushing for routine diagnostics (DIII).

After CVC removal

- Perform a microbiological examination of the CVC tip (AIIt).

$D T T P$, differential time to positivity; $C V C$, central venous catheter

of catheter access sites prior to manipulation. In addition to these measures, close collaboration between the primary caring oncologist and infection control/microbiology and ICU physicians is essential in the prevention of CRIs.

Several institutions have issued recommendations on prevention of CRI that are largely based on studies not exclusively focusing on cancer patients. Nonetheless, recent smaller studies in cancer patients show similar results in terms of the effectiveness of education and surveillance methods to prevent CRIs in cancer patients [71, 110-113]. In a recent study, Chaftari and colleagues conducted a quality improvement project focusing on simultaneous peripheral and central blood culture drawing with accurate source labeling in cancer patients. After staff education and monitoring, the average blood culture source labeling improved from a baseline of 48 to $70 \%$ and identification of the $\mathrm{CVC}$ as source of bacteremia was successful in $88 \%$ of cases compared with $36 \%$ at baseline $(P=0.0003)$, suggesting that education measures are equally effective in cancer patients for the prevention of CRIs [110].

Screening for CRIs in asymptomatic patients by routine withdrawal of blood cultures is not recommended, as weekly or even daily blood culturing is not effective in the earlier detection of CRI in cancer patients including HSCT recipients [114-117].

\section{Sterile precautions, skin antisepsis, and CVC replacement}

CVC insertion should be attempted under maximal sterile barrier precautions including sterile gown, gloves, and cap and 
Fig. 1 Diagnostic procedures in case of suspected catheter-related infection (CRI)

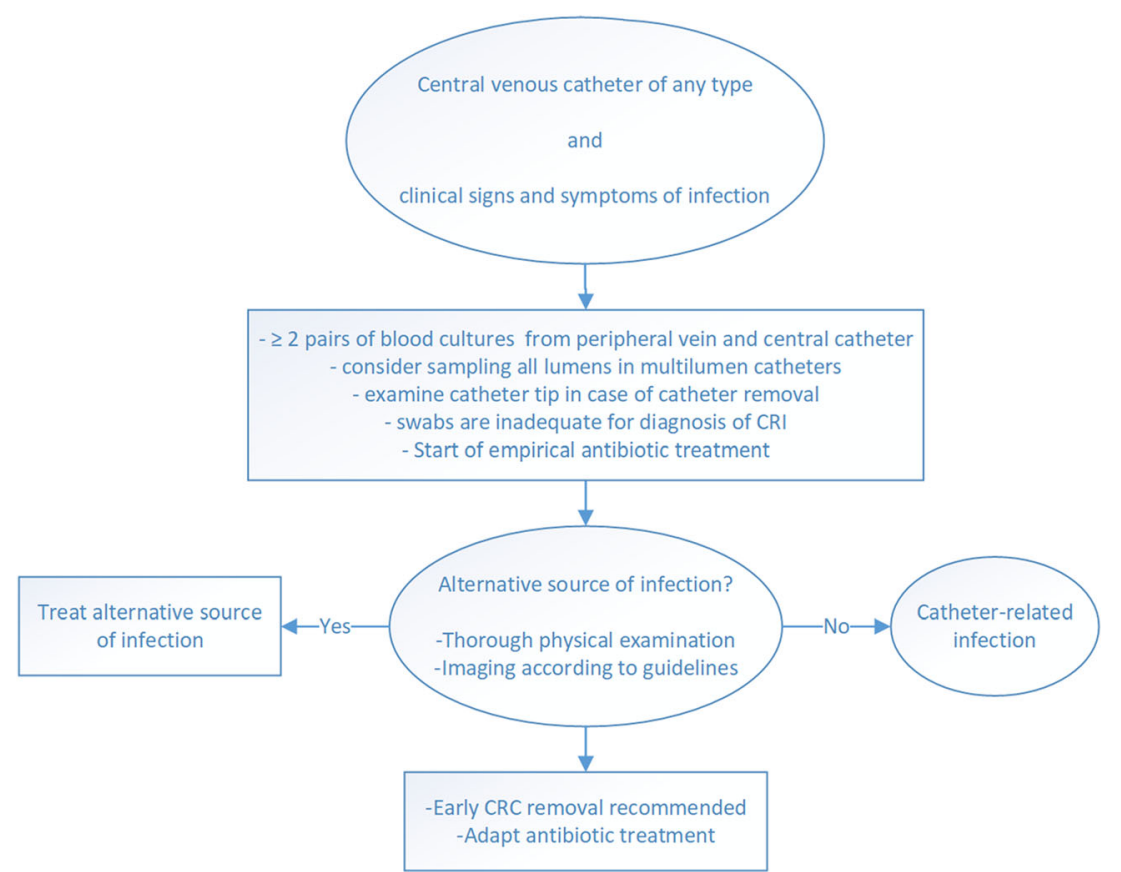

using a large sterile drape and implementing aseptic bundles as they decrease the risk of CRI [102, 118].

Ultrasound (US)-guided central venous catheterization is associated with lower rates of pneumothorax and other mechanical complications and may reduce the number of cannulation attempts [119-121]. Although the impact on the incidence of CRI is less clear, central venous cannulation using US is recommended for the avoidance of mechanical complications and the reduction of cannulation attempts with a possible positive impact on the incidence of CRI [119, 122].

Cutaneous antisepsis using $>0.5 \%$ chlorhexidine alcohol-based solution (CBA) results in lower rates of CRBSI compared with $10 \%$ polyvidone-iodine or $70 \%$ alcohol-only solutions as shown in studies and meta-analyses, although alcoholic polyvidone-iodine solutions (APVP) or $70 \%$ propranolol may be safe alternatives in case of allergy or intolerance to chlorhexidine [123-131]. Accordingly, the use of antiseptic agents containing only alcohol is not recommended for insertion of CVCs by institutional guidelines such as the KRINKO [27]. Several studies have analyzed and tested the sequential or parallel application of disinfectants such as CBA and A-PVP [69, 132-134]. For instance, sequential CBA with A-PVP was superior to either of the regimens alone in terms of a lower rate of CVC tip colonization in 119 patients on normal wards and ICUs [134]. A recent meta-analysis analyzing several studies concluded that sequential antiseptic use reduces the likelihood of CVC colonization compared with the use of either agent alone, although the impact on the risk of CRBSI risk is less clear [132]. Therefore, combinations of CBA with A-PVA or octenidine/propranolol solutions are alternatives for cutaneous antisepsis. If necessary, the insertion site should be cleaned prior to disinfection.

Daily chlorhexidine ( $\mathrm{CHX}$ ) bathing reduces the incidence of CRBSI in patients in ICUs. However, the impact of CHX bathing on CRBSI in cancer patients has not been well studied and is therefore not recommended in clinical routine [135, 136].

Although longer dwelling times of CVCs increase the risk of CRBSI, routine replacement did not reduce the incidence of CRBSI in adult ICU patients $[137,138]$. A large cohort analysis examined CVC duration to predict CRBSI in 1194 cancer patients and failed to determine an optimal cutoff time point at which a prophylactic CVC exchange would prevent CRBSI [33]. Thus, routine replacement of CVC is not recommended [27]. Infusion and tubing systems should be replaced as previously recommended [10, 139].

\section{CVC site dressing and anti-infective caps}

Sterile gauze or transparent film should be used as dressing to cover the CVC insertion site [25]. CVC gauze dressings should be replaced every 2 days, transparent dressings once weekly, unless there are signs of local contamination, inflammation, or detachment $[1,25,27,140]$. Whether the use of gauze or transparent dressings is preferable in terms of lower CRI rates was addressed in two recent meta-analyses [141, 142]. Dang and colleagues reported that transparent dressings were associated with a lower risk of CRBSI [142]. In contrast, an analysis of 22 studies did not find sufficient evidence for a difference in the rate of CRBSI between different non- 
Table 4 Prevention of CVC-related infections (CRI)

- Avoid unnecessary catheterization and remove CVCs no longer required (AIIt).

- Implement education programs and bundles for nurses and physicians including continuous surveillance and feedback to reduce the incidence of CRIs (AIIt).

- Compliance with hygiene principles during insertion and standardized aseptic placement and handling of the catheter help to avoid CRIs (AIIt).

- Alcoholic chlorhexidine solution with polyvidone-iodine solutions or octenidine/propranolol solutions should be used for disinfection of the catheter insertion site (AI).

- Ultrasound-guided placement ultrasound may reduce the rate of mechanical complications (AIIt) and the number of cannulation attempts with a possible impact on the incidence of CRI (CIIt).

- Avoid femoral catheterization (DIIt).

- Catheter fixation using sutureless devices might reduce the risk of CRI (BI).

- Cover insertion site using sterile gauze or transparent film (AI).

- Replace CVC gauze dressings every 2 days and transparent dressings once weekly, unless there are signs of local contamination, inflammation, or detachment (BI).

- Chlorhexidine-containing dressings, preferably transparent chlorhexidine-impregnated gel dressings, may be used alternatively as they might reduce the risk of CRIs (BI).

- Antimicrobial-impregnated CVCs may be useful in patients with long-term CVCs in case of persisting high rate of CRI despite implementation of educational programs and appropriate $\mathrm{CVC}$ bundles (CIIt).

- Antibiotic lock solutions should be limited to persisting high baseline rates of CRI in high-risk patients with long-term catheters (BI).

- Do not screen for CRIs in asymptomatic patients by routine withdrawal of blood cultures (DII).

- Do not apply systemic prophylactic antibiotic treatment prior to catheter insertion (DI).

- Do not apply topical antibiotic ointments for reducing staphylococcal colonization at the CVC insertion site (DII).

- Routine replacement does not reduce the incidence of CRI (DI).

$C R I$, catheter-related infection; $C R B S I$, catheter-related bloodstream infection; $C V C$, central venous catheter

impregnated dressings [141]. Similarly, a recent systematic review in HSCT recipients found no difference between the type of dressing and the incidence of CRBSI [143]. Therefore, gauze, tape, or transparent polyurethane dressings can be recommended for CVC site insertion dressing without clear preference of one over the other.

$\mathrm{CHX}$-impregnated dressings were tested in cancer and ICU patients in randomized trials showing a reduction in CRI rates compared with standard dressings, and this finding could be confirmed in a recent systematic review and meta-analysis [31, 144-148]. A recent multicenter randomized trial studied the use of dressings containing CHX-containing gel pads compared with standard non-impregnated dressings in 613 neutropenic cancer patients using the stringent definition of definite CRBSI and probable CRBSI [10, 31]. Although difference in the primary end point of definite CRBSI after 14 days did not meet statistical significance, both definite plus probable CRBSI (dpCRBSI14) after 14 days and overall definite plus probable CRBSI (dpCRBSI) were significantly less frequent in the CHX group compared with control. Rates of dpCRBSI14 were 6.5\% (20/307) in the CHX group compared with $11 \%(34 / 306)$ in the control group $(P=0.047)$, and dpCRBSI occurred in $10.4 \%(32 / 307)$ and $17 \%(52 / 306)$ in the CHX and the control groups, respectively $(P=0.019)$. Moreover, $\mathrm{CHX}$ dressings were well tolerated as the frequency of dressing intolerance with cutaneous and soft tissue abnormalities at the contact area was similar in both groups (12.4\% and $11.8 \% ; P=0.901)$ [31]. Therefore, the use of CHX-containing dressings might be helpful for the prevention of CRIs in cancer patients, preferably transparent CHXimpregnated gel dressings, as CHX sponges might conceal the insertion site and increase the risk of dressing detachment $[146,147]$. As CRIs are often preceded by hub colonization, disinfectant caps have been tested in smaller observational trials and might be a promising approach to reduce the incidence of CRIs in cancer patients $[149,150]$.

\section{Choice of CVC, sutureless devices, and impact of catheterization site}

Randomized trials and meta-analyses have shown no difference in risk of CRIs between single- or multiple-lumen CVC, and therefore, a preferred use of single-lumen catheters is not supported [151-153]. The use of sutureless devices was found to reduce the risk of CRI in a randomized study and in two meta-analyses accounting for multiple treatments [141, 142, 154].

The association of catheterization site and CRI has been studied in several earlier studies and meta-analyses [155-158]. Overall, the insertion in femoral sites has been associated with a higher risk of infections and thrombotic complications compared with subclavian and internal jugular CVCs. In a recent large randomized study comparing different insertion sites in more than 3000 adult patients on ICUs, the risk of an event in composite outcome of CRBSI and symptomatic deep-vein thrombosis was significantly higher in the femoral group compared with a subclavian approach [159]. In accordance, two meta-analyses concluded that the use of femoral catheters increases the risk of CRBSI compared with internal jugular and subclavian catheters $[160,161]$. Therefore, femoral catheterization should be avoided. Subclavian insertion might be preferable over internal jugular, as colonization risk and risk of CRBSI might be slightly lower at subclavian sites [159-161]. However, in a recent retrospective singlecenter analysis on 56 patients undergoing allogeneic HSCT, there were no differences in the frequency of CLABSI, deepvein thrombosis, pneumothorax, and catheter lumen 
obstruction between catheters inserted into either internal jugular or subclavian vein [162]. Of note, in larger studies, insertion at the subclavian site was associated with higher risk of mechanical complications, in particular pneumothorax and hemorrhage $[159,163,164]$.

\section{Antimicrobially impregnated CVCs}

Multiple studies and meta-analyses showed a reduction in catheter colonization by use of antiseptic-coated CVCs, usually using CVCs coated with CHX, silver sulfadiazine, or both [165-169]. However, a reduction in CRBSI rates by the use of antimicrobial CVCs was not consistently found. The use of minocycline/rifampicin or miconazole/rifampicin-coated catheters resulted in a reduced incidence of CRI in the majority of trials performed, and despite initial concerns, no higher incidence of antibiotic resistance was observed with the use of antibiotic CVCs [170-177]. Notably, in the largest trial exclusively including cancer patients, the intervention was tested in long-term catheters with catheters used for more than 2 months [173]. In conclusion, the use of antimicrobial-impregnated CVCs may be useful in patients with long-term CVC in case of persisting high rate of CRI despite implementation of educational programs and appropriate CVC bundles.

\section{Systemic and topical antibiotic prophylaxis}

Systemic antibiotic prophylaxis before CVC insertion does not reduce CRIs in cancer patients [178]. A recent singlecenter study on fluoroquinolone prophylaxis in recipients of autologous HSCT during neutropenia suggested a benefit in reduction of CRIs. However, this was a retrospective study that used the incidence of CLABSI rather than CRBSI as primary endpoint [179]. Therefore, systemic antimicrobial prophylaxis before CVC insertion is not recommended for the prevention of CRIs. Accordingly, as topical antibiotics have not been shown to reduce risk of CRIs and might increase the risk of antibiotic resistance, the use of topical antibiotics is not recommended for the prevention of CRI [180].

\section{Antimicrobial lock solutions for prevention of CRIs}

Heparin lock solutions are commonly used, although saline solution might be a safe alternative as it proved non-inferior in terms of functional problems and CVC-related bacteremia in a randomized trial including 802 cancer patients with totally implantable venous access devices [181]. Taurolidinecitrate-heparin did not result in significantly less CVC hub colonization and CRBSI than placebo in neutropenic hematologic patients in a prospective multicenter trial involving 150 patients with non-tunneled CVCs [182]. Ethanol 70\% lock solution has been studied in several randomized trials including heterogenous study populations with conflicting results. In a placebo-controlled randomized trial including 64 hematologic patients with cuffed subclavian Hickman catheters, daily administrations of ethanol locks effectively reduced the incidence of CABSI from 0.60/100 catheter-days in the ethanol group to $3.11 / 100$ catheter-days in the control group [183]. Similarly, 2-hour ethanol locks once weekly resulted in a reduced CABSI incidence in a randomized trial in 307 pediatric oncology patients, predominantly less Gram-positive CLABSIs [184]. In contrast, two recent randomized trials, one of those using the more stringent CRBSI definition, failed to show a significant reduction of CRIs in cancer patients by use of ethanol locks $[185,186]$.

As CRIs are in most cases preceded by CVC colonization, antibiotic lock solutions were tested as means of preventing bacterial colonization and subsequent CRI. Instillation of vancomycin resulted in lower rates of CVC hub colonization with Gram-positive bacteria and subsequent bacteremia during neutropenia in a randomized single-center study including 120 cancer patients [187]. Three meta-analyses suggested a reduction of CRI by antibiotic locks (ALT) [178, 188, 189]. However, the studies included were heterogenous as the populations studied were in part pediatric cancer patients or hemodialysis patients and the treatment protocols varied substantially. Therefore, ALT should be limited to persisting high baseline rates of CRI in high-risk patients with long-term catheters, and the potential beneficial effects of ALT must be balanced against the potential for allergic reactions, toxicity, and emergence of antimicrobial resistance.

\section{Management}

Recommendations for the management of CRI are summarized in Table 5 and in Table 6.

\section{Catheter removal}

Antimicrobial therapy and removal of the CVC are crucial in the treatment of patients with suspected CRI. As retention of the CVC in patients with suspected CRI can result in treatment failure or recurrence of infection in spite of antibiotic therapy, CVC removal is encouraged in all patients with CRI whenever possible [1, 21, 38, 86, 190-192]. Although CVC removal and reinsertion may be burdensome for cancer patients, early CVC removal is particularly encouraged in patients with deteriorating clinical state, sepsis, or septic shock and in case of severe complications such as endocarditis, septic thrombosis, abscess formations, or osteomyelitis [193]. In addition, in patients with tunnel or pocket infection, CVC removal is usually required [1]. CVC exchange is often cumbersome and associated with significant risks in thrombocytopenic patients and may not always be feasible. However, retention of CVC has not been tested as a strategy in any randomized trial in patients with suspected CRI. Therefore, in severely thrombocytopenic 
Table 5 Management of CVC-related infections (CRI)

- Remove the CVC in patients with CRI whenever possible (AIIt).

- $\mathrm{CVC}$ removal is necessary in patients with tunnel and pocket infections (BIII).

- In severely thrombocytopenic patients with limited venous access, the risk of catheter reinsertion should be carefully weighed against the risk of patient deterioration and prolongation of the infection (BIII).

- CVC exchange over a guidewire is not recommended as an alternative approach to removal (DIII).

- Early CVC removal is particularly encouraged in patients with deteriorating clinical state, sepsis, or septic shock and in case of severe complications such as endocarditis, septic thrombosis, abscess formations, or osteomyelitis (BIII). In case of preserved catheter, prompt removal is warranted in any case of clinical deterioration or continued positive blood cultures $72 \mathrm{~h}$ after initiation of therapy in spite of appropriate antimicrobial therapy.

- Early CVC removal is always recommended in patients with CRBSI due to $S$. aureus (AIIt).

- Early catheter removal is always recommended in patients with CRBSI due to Candida spp. (AIIt).

- Catheter removal within 48-72 $\mathrm{h}$ is recommended in case of CRBSI caused by Gram-negative bacteria (BIIt).

- Preservation of CVC may be initially attempted in clinically stable patients in the presence of coagulase-negative staphylococci or Corynebacterium jeikeium (BIIt).

- An antimicrobial lock technique may be an option for "highly needed" infected implantable catheters in conjunction with systemic antibiotic therapy (BIII).

- Empirical glycopeptide therapy is not recommended (DI).

- Modify systemic antibiotic treatment according to microbiological results of susceptibility testing (AII).

- Initial antimicrobial regimen may be continued in case of clinical response to empiric treatment without microbiological evidence of insufficient antibiotic coverage (BIII).

- For uncomplicated CRI, continue antibiotic treatment $\geq 7$ days depending on the causative pathogen, counting the day of the first sterile blood culture as day one of treatment (AII).

- At least 2 weeks of systemic antimicrobial treatment is recommended in immunocompromised patients (BIII).

$C R I$, catheter-related infection; $C R B S I$, catheter-related bloodstream infection; $C V C$, central venous catheter

patients with limited venous access, the risk of CVC reinsertion should be carefully weighed against the risk of patient deterioration and prolongation of the CRI.

Several studies in patients with $S$. aureus bacteremia indicate an increased risk for hematogenous complications, relapse of infection, and death of infection if the CVC is retained after detection of $S$. aureus [194, 195]. Retrospective analyses reported successful preservation of Hickman catheters in patients with $S$. aureus bacteremia in 18-60\% of analyzed cases. However, these studies are likely to be biased due to selection of patients with successful salvage [196, 197]. Moreover, El Zakhem and colleagues recently analyzed 299 cancer patients with 304 episodes of $S$. aureus CLABSI and reported a higher rate of relapse in patients whose $\mathrm{CVC}$ was retained beyond
3 days compared with those whose CVC was removed or exchanged within the first 3 days from the onset of bacteremia [198]. Therefore, early CVC removal is recommended in patients with suspected $S$. aureus CRI.

Retrospective studies suggest that mucositis and the gastrointestinal tract rather than the CVC might be the cause for candidemia in a large proportion of cancer patients with candidemia [199, 200]. However, the diagnosis of CRI in patients with candidemia without CVC removal is challenging, since a DTTP of $>2 \mathrm{~h}$ is unreliable in excluding Candidarelated CRBSI, and the cutoff DTTP for different Candida spp. is not established and may vary substantially [16-18]. In two prospective observational studies [201, 202] and a retrospective analysis of two prospective trials testing the efficacy of antifungal drugs [203], early CVC removal was not associated with any clinical benefit in patients with candidemia and CVC. However, these studies were not limited to cancer patients, included only a minority of neutropenic patients, and did not use stringent criteria for the definition of CRBSI. In contrast, Raad and colleagues retrospectively analyzed 404 cancer patients with candidemia and CVCs and found that $\mathrm{CVC}$ removal within $72 \mathrm{~h}$ after onset of candidemia improved the response to antifungal therapy in patients with Candida-related CRBSI [199]. Similarly, findings from retrospective studies and a prospective cohort study in cancer patients with candidemia and systematic reviews indicate a decreased mortality in patients with CVC removal [204-206]. Therefore, prompt CVC removal is recommended in cancer patients with candidemia and yeast-related fungemias (e.g., Rhodotorula spp.) other than caused by Cryptococcus spp. [207, 208].

In patients with CRBSI caused by Gram-negative bacteria, CVC retention resulted in higher risk of relapse of Gramnegative bacteremia [8]. Furthermore, early CVC removal was associated with lower mortality in a single-center retrospective study including 78 cases of Gram-negative CRBSI (43 definite and 35 probable), of which about one-third had cancer [209]. Another retrospective study on 300 cancer patients with Gram-negative bloodstream infections showed that CVC removal within 2 days of pathogen detection was associated with lower overall mortality in CRBSI patients (overall mortality rate at 3-month follow-up: $3 \%$ and $19 \%, P=0.01$, in patients with early and delayed CVC removal, respectively) [191]. Similarly, prompt CVC removal was found to be associated with a better response to antimicrobial therapy and lower risk of mortality in patients with CRBSI related to Stenotrophomonas spp. [209-211]. Therefore, prompt CVC removal (within 48-72 h) is recommended in case of CRBSI caused by Gram-negative bacteria.

A recent study on 184 CRBSI episodes caused by CoNS including $41 \%$ cancer patients found that withholding antimicrobial therapy in CoNS CRBSI following CVC removal was not associated with non-resolved CRIs or mortality [212]. 
Table 6 Antimicrobial therapy of CRI depending on causative pathogen

\begin{tabular}{|c|c|c|}
\hline Pathogen & Therapy & Duration $^{\mathrm{a}}$ \\
\hline $\begin{array}{l}\text { Staphylococcus aureus } \\
\quad \text { (methicillin-sensitive) }^{\mathrm{b}}\end{array}$ & Isoxazolyl penicillin (anti-staphylococcal penicillin) & $\geq 2$ weeks $^{\mathrm{c}}$ \\
\hline \multirow{2}{*}{$\begin{array}{l}\text { Staphylococcus aureus } \\
\quad \text { (methicillin-resistant) }^{\mathrm{b}}\end{array}$} & \multirow[t]{2}{*}{ Glycopeptide, linezolid, daptomycin } & $\geq 2$ weeks $^{\mathrm{c}}$ \\
\hline & & $\begin{array}{l}4-6 \text { weeks in case of complicated } \\
\text { infection }\end{array}$ \\
\hline $\begin{array}{l}\text { Coagulase-negative } \\
\text { staphylococci }\end{array}$ & $\begin{array}{l}\text { According to susceptibility pattern; glycopeptides only in case of methicillin } \\
\text { resistance }\end{array}$ & $\begin{array}{l}\text { 5-7 days after defervescence (in pts } \\
\text { with persistent neutropenia) }\end{array}$ \\
\hline Enterococci & $\begin{array}{l}\text { Aminopenicillin; glycopeptide and aminoglycoside in case of ampicillin resistance; } \\
\text { linezolid in case of vancomycin resistance }\end{array}$ & $\begin{array}{l}\text { 5-7 days after defervescence (in pts } \\
\text { with persistent neutropenia) }\end{array}$ \\
\hline \multirow[t]{2}{*}{ Stenotrophomonas spp. } & Co-trimoxazole & \multirow[t]{2}{*}{$\geq 2$ weeks } \\
\hline & According to susceptibility pattern in case of allergy (e.g., levofloxacin) & \\
\hline Pseudomonas spp. & According to susceptibility pattern & $\geq 2$ weeks \\
\hline Candida albicans ${ }^{\mathrm{b}}$ & $\begin{array}{l}\text { Echinocandin according to susceptibility pattern or amphotericin B lipid-based } \\
\text { formulations after stabilization step down to fluconazole }\end{array}$ & $\geq 2$ weeks \\
\hline $\begin{array}{l}\text { Non-albicans Candida } \\
\text { spp. }\end{array}$ & $\begin{array}{l}\text { Echinocandin; step down to azole according to susceptibility pattern or } \\
\text { amphotericin B lipid-based }\end{array}$ & $\begin{array}{l}\geq 2 \text { weeks (after first sterile blood } \\
\text { culture) }\end{array}$ \\
\hline All other pathogens & According to susceptibility pattern & Not defined \\
\hline
\end{tabular}

${ }^{\text {a }}$ Follow-up blood cultures necessary after cessation of antibiotic/antifungal therapy in order to rule out persistence of infection (AII)

${ }^{\mathrm{b}}$ Early CVC removal required (AII)

${ }^{\mathrm{c}}$ Higher incidence of organ infection if treatment is continued for $<2$ weeks (AII)

CVC, central venous catheter; $p t s$, patients

In patients with implanted long-term catheters such as Hickman catheters and port catheters, two retrospective cohort studies analyzed the effect of CVC removal in patients with CoNS CRBSI. The investigators found no impact on mortality or the resolution of bacteremia, although a higher risk of recurrence of infection was detectable $[86,213]$. Thus, in hemodynamically stable patients of urgent need for long-term venous access and limited options, long-term CVCs may be left in place under careful surveillance and with systemic antibacterial therapy. Similarly, in retrospective studies examining the effect of CVC removal in patients with Corynebacterium jeikeium causing BSI and CRI, retention of the CVC was not associated with higher mortality or recurrence of infection if systemic antibiotic treatment was administered [214, 215]. Accordingly, in patients with C. jeikeium CRI, CVC retention along with systemic antibiotic treatment may be acceptable in hemodynamically stable patients with tunneled CVC under careful surveillance.

In patients with CVC left in place after onset of symptoms, $\mathrm{CVC}$ removal is warranted in any case of clinical deterioration or continued positive blood cultures $72 \mathrm{~h}$ after initiation of therapy in spite of appropriate antimicrobial therapy [1].

CVC exchange over a guidewire may induce bacteremia and therefore cannot be recommended as alternative approach to CVC removal. CVC exchange over a guidewire and replacement with a minocycline/rifampin-coated CVC were shown to prevent biofilm formation [216] and appeared to be safe and improved response to systemic antimicrobial therapy in one matched retrospective cohort study in cancer patients with CRI [217]. This approach may be feasible in selected patients when the risk of reinsertion outweighs the persistence or relapse of CRI.

\section{Antibiotic lock therapy}

ALT is conducted by instillation of antibiotic solutions at high concentrations mostly in combination with anticoagulants such as heparin or EDTA (ethylenediaminetetraacetate) into a CVC lumen for several hours. ALT was studied in small randomized trials and retrospective studies as treatment in conjunction with systemic antibiotic therapy for patients with implantable CVCs showing efficacy in up to $100 \%$ [218-220]. However, the procedure of ALT is not standardized, and considerable variability between different protocols concerning the antibiotic solutions used, antibiotic concentrations, dwelling time, the duration of ALT, and the simultaneous use of the infected catheter has been reported [221]. Moreover, ALT may be less effective in CRBSI caused by S. aureus, Candida spp., and other microorganisms embedded in biofilms [222]. In conclusion, ALT may be a treatment option for patients with infected implantable CVCs and limited options for vascular access in conjunction with systemic antibiotic therapy. 
Several antiseptic solutions such as ethanol or combinations of antibiotics with antiseptic solutions have been tested in smaller studies in patients with bacteremia [223-226]. In a randomized study using either ethanol $70 \%$ or saline in 94 children with cancer as treatment or secondary prophylaxis for CLABSI, ALT did not prevent CLABSI treatment failure and it increased CVC occlusion [224]. In contrast, approaches using minocycline-EDTA-ethanol solution while leaving the catheter in place compared favorably in 30 adult cancer patients with CLABSI in terms of duration of systemic antimicrobial therapy and mechanical complications. However, as this study only used a historic control of patients, the results should be confirmed in a randomized trial [227].

\section{Systemic antimicrobial treatment}

Systemic antibiotic treatment is the second mainstay of treatment of CRI and should be started immediately after sampling of blood cultures. The choice of empiric antibiotic treatment depends on the clinical severity of the infection, the patient's comorbidities, and potential known colonization with MDR bacteria, as well as local resistance patterns $[45,87]$. In high-risk neutropenic patients, piperacillin/tazobactam, imipenem, and meropenem can be suitable options for first-line empirical antibacterial therapy [87]. Empiric addition of glycopeptides prior to microbiological evidence of Gram-positive CRI is discouraged, as this treatment might result in an increase in antibiotic resistance and additional toxicity and does not improve outcomes of febrile neutropenic patients with cancer as shown in several studies and a recent metaanalysis [228].

Empiric treatment should be modified according to microbiological results of susceptibility testing. In patients clinically responding to empiric treatment without microbiological evidence of insufficient antibiotic coverage, the initial antimicrobial regimen may be continued. Repeated blood cultures are recommended to account for the first day of negative blood culture results to guide treatment duration and to detect complicated CRI with prolonged microbiological evidence of bacteremia in spite of antimicrobial treatment. Duration of the treatment depends on the pathogen detected, the resolution of symptoms, the absence or emergence of complications such as endocarditis or osteomyelitis, and clinical, microbiological, and laboratory evidence of response to antimicrobial treatment $[45,87]$.

Depending on the causative pathogen and for uncomplicated CRI, antibiotic treatment should be continued for at least 7 days, counting the day of the first sterile blood culture as day one of treatment and catheter removal [1, 229, 230]. Longer treatment duration may be indicated in case of complications such as endocarditis and for treatment of specific pathogens such as S. aureus, Candida spp. and other fungi [207],
Stenotrophomonas spp., and others (Table 6). Optimal treatment duration in neutropenic cancer patients is currently unclear, and whether treatment should be continued until resolution of neutropenia remains controversial as specific data from high-quality studies in neutropenic patients are lacking [231]. With respect to specific clinical scenarios such as nonresponse to antimicrobial treatment or the management of sepsis, we refer to recent AGIHO guidelines [45, 46, 87].

\section{Conclusion}

In this guideline, we summarize recommendations on definition, diagnosis, management, and prevention of CRI in cancer patients. This publication replaces the current version of our guideline and adds specific recommendations on cancer patients in addition to institutional and regulatory guidelines.

Diagnostic procedures for the detection of CRIs should be initiated upon clinical signs and symptoms of infection in patients with any type of indwelling CVC. In patients with suspected CRI, at least two pairs of blood cultures with adequate quantity of blood should be taken simultaneously from the CVC and a peripheral vein. Although the DTTP has been reported as a sensitive and specific diagnostic marker for CRBSI, recent studies suggest that the DTTP is inaccurate for the diagnosis of S. aureus - and Candida spp.-associated CRBSI. In case of suspected or diagnosed CRI, the mainstays of treatment are antimicrobial therapy and removal of the CVC. As CVC retention may result in treatment failure or recurrence of infection in spite of antibiotic therapy, removal is encouraged whenever possible. CVC retention along with systemic antibiotic treatment may be acceptable in hemodynamically stable patients under careful surveillance in certain cases and for selected pathogens. In any case, removal is warranted in case of clinical deterioration or continued positive blood cultures $72 \mathrm{~h}$ after initiation of appropriate antimicrobial treatment. Systemic antibiotic treatment should be initiated immediately after sampling of blood cultures and chosen depending on severity of the infection, patient's comorbidities, and potential colonization with MDR pathogens as well as local resistance patterns.

Authors' contributions All authors contributed to the guideline conception and design. Material preparation, data collection, and analysis were performed by all authors. The first draft of the manuscript was written by $\mathrm{BB}$, and all authors commented on previous versions of the manuscript. All authors read and approved the final manuscript.

Funding Open Access funding enabled and organized by Projekt DEAL. Travel expenses and organizational costs of meetings and consensus conferences were funded by the Infectious Diseases Working Party of the German Society of Hematology and Medical Oncology (DGHO). No additional funding was provided for this guideline.

Data availability Not applicable. 


\section{Compliance with ethical standards}

Conflict of interest Boris Böll received grants from Astra Zeneca and Sanofi; personal fees from Celgene, MSD, Roche, and Takeda; and personal fees from Baxalta, Mundipharma, and J\&J outside the submitted work.

Dieter Buchheidt received research grants from Gilead Sciences and Pfizer; served on the speakers' bureau of Gilead Sciences, Merck Sharp \& Dohme/Merck, and Pfizer; and received travel grants from Gilead Sciences, Merck Sharp \& Dohme/Merck, and Pfizer, outside the submitted work.

Justin Hasenkamp received honoraria as a consultant from AMGEN, Bristol-Myers Squibb, Celgene, Gilead Science, Jazz Pharmaceuticals, MSD Sharp \& Dohme, Neovii, Novartis Pharma, and Mundipharma and payment for educational presentations (written or oral) from Deutscher Ärzte-Verlag, Georg Thieme Verlag, MedKom Akademie, and NewConceptOncology GmbH outside the submitted work.

Michael Koldehoff received lecture honoraria from CSL Behring and AURIKAMED outside the submitted work.

Olaf Penack has received honoraria and travel support from Astellas, Gilead, Jazz, MSD, Neovii Biotech, and Pfizer. He has received research support from Bio Rad, Gilead, Incyte, Jazz, Neovii Biotech, Pierre Fabre, Sanofi, and Takeda. He is a member of the advisory board to Jazz, Gilead, MSD, Omeros, and SOBI.

Markus Ruhnke was a consultant to Basilea, Daiichi Sankyo, Kedplasma, Janssen, and Scynexis and received payment for development of educational presentations from Basilea and Janssen.

Matthias Kochanek received lecture honoraria from Astellas, Gilead, MSD, and Pfizer outside the submitted work.

Sibylle C. Mellinghoff was a consultant to Octapharma. She has received research funding by the DMyKG, the German Centre for Infection Research, and the University Hospital of Cologne.

All other authors declare no potential competing interests.

Ethics approval Not applicable.

\section{Consent to participate Not applicable.}

Consent for publication Not applicable.

Code availability Not applicable.

Open Access This article is licensed under a Creative Commons Attribution 4.0 International License, which permits use, sharing, adaptation, distribution and reproduction in any medium or format, as long as you give appropriate credit to the original author(s) and the source, provide a link to the Creative Commons licence, and indicate if changes were made. The images or other third party material in this article are included in the article's Creative Commons licence, unless indicated otherwise in a credit line to the material. If material is not included in the article's Creative Commons licence and your intended use is not permitted by statutory regulation or exceeds the permitted use, you will need to obtain permission directly from the copyright holder. To view a copy of this licence, visit http://creativecommons.org/licenses/by/4.0/.

\section{References}

1. Mermel LA, Allon M, Bouza E et al (2009) Clinical practice guidelines for the diagnosis and management of intravascular catheter-related infection: 2009 update by the Infectious
Diseases Society of America. Clin Infect Dis 49:1-45. https:// doi.org/10.1086/599376

2. Raad I, Chaftari AM (2014) Advances in prevention and management of central line-associated bloodstream infections in patients with cancer. Clin Infect Dis 59:S340-S343. https://doi.org/10. 1093/cid/ciu670

3. Gallieni M, Pittiruti M, Biffi R (2008) Vascular access in oncology patients. CA Cancer J Clin 58:323-346. https://doi.org/10. 3322/ca.2008.0015

4. Aghdassi SJS, Schröder C, Gruhl D et al (2019) Point prevalence survey of peripheral venous catheter usage in a large tertiary care university hospital in Germany. Antimicrob Resist Infect Control 8:1-7. https://doi.org/10.1186/s13756-019-0468-8

5. Baier C, Linke L, Eder M et al (2020) Incidence, risk factors and healthcare costs of central line-associated nosocomial bloodstream infections in hematologic and oncologic patients. PLoS One 15:111. https://doi.org/10.1371/journal.pone.0227772

6. Rabensteiner J, Theiler G, Duettmann W et al (2015) Detection of central venous catheter-related bloodstream infections in haematooncological patients. Eur J Clin Investig 45:824-832. https://doi.org/10.1111/eci.12477

7. Hanna HA, Raad I (2001) Blood products: a significant risk factor for long-term catheter-related bloodstream infections in cancer patients. Infect Control Hosp Epidemiol 22:165-166. https://doi. org/10.1086/501885

8. Hanna H, Afif C, Alakech B et al (2004) Central venous catheterrelated bacteremia due to Gram-negative bacilli: significance of catheter removal in preventing relapse. Infect Control Hosp Epidemiol 25:646-649. https://doi.org/10.1086/502455

9. Umscheid CA, Mitchell MD, Doshi JA et al (2011) Estimating the proportion of healthcare-associated infections that are reasonably preventable and the related mortality and costs. Infect Control Hosp Epidemiol 32:101-114. https://doi.org/10.1086/657912

10. Hentrich M, Schalk E, Schmidt-Hieber M et al (2014) Central venous catheter-related infections in hematology and oncology: 2012 updated guidelines on diagnosis, management and prevention by the Infectious Diseases Working Party of the German Society of Hematology and Medical Oncology. Ann Oncol 25: 936-947. https://doi.org/10.1093/annonc/mdt545

11. Kish MA (2001) Guide to development of practice guidelines. Clin Infect Dis 32:851-854. https://doi.org/10.1086/319366

12. Chatzinikolaou I, Hanna H, Hachem R et al (2004) Differential quantitative blood cultures for the diagnosis of catheter-related bloodstream infections associated with short- and long-term catheters: a prospective study. Diagn Microbiol Infect Dis 50:167172. https://doi.org/10.1016/j.diagmicrobio.2004.07.007

13. Safdar N, Fine JP, Maki DG (2005) Meta-analysis: methods for diagnosing intravascular device-related bloodstream infection. Ann Intern Med

14. Kaasch AJ, Rieg S, Hellmich M et al (2014) Differential time to positivity is not predictive for central line-related Staphylococcus aureus bloodstream infection in routine clinical care. J Inf Secur. https://doi.org/10.1016/j.jinf.2013.08.006

15. Bouzidi H, Emirian A, Marty A et al (2018) Differential time to positivity of central and peripheral blood cultures is inaccurate for the diagnosis of Staphylococcus aureus long-term catheter-related sepsis. J Hosp Infect 99:192-199. https://doi.org/10.1016/j.jhin. 2018.01.010

16. Park KH, Lee MS, Lee SO et al (2014) Diagnostic usefulness of differential time to positivity for catheter-related candidemia. J Clin Microbiol 52:2566-2572. https://doi.org/10.1128/JCM. 00605-14

17. Bouza E, Alcalá L, Muñoz P et al (2013) Can microbiologists help to assess catheter involvement in candidaemic patients before removal? Clin Microbiol Infect 19. https://doi.org/10.1111/14690691.12096 
18. Jo KM, Choi S, Jung KH et al (2020) Diagnostic usefulness of differential time to positivity in neutropenic cancer patients with suspected catheter-related candidemia. Med Mycol 58:137-140. https://doi.org/10.1093/mmy/myz028

19. Gits-Muselli M, Villiers S, Hamane S et al (2020) Time to and differential time to blood culture positivity for assessing catheterrelated yeast fungaemia: a longitudinal, 7-year study in a single university hospital. Mycoses 63:95-103. https://doi.org/10.1111/ myc. 13024

20. See I, Iwamoto M, Allen-Bridson K et al (2013) Mucosal barrier injury laboratory-confirmed bloodstream infection: results from a field test of a new National Healthcare Safety Network definition. Infect Control Hosp Epidemiol 34:769-776. https://doi.org/10. $1086 / 671281$

21. Zakhour R, Chaftari AM, Raad II (2016) Catheter-related infections in patients with haematological malignancies: novel preventive and therapeutic strategies. Lancet Infect Dis 16:e241-e250. https://doi.org/10.1016/S1473-3099(16)30213-4

22. Chaftari AM, Jordan M, Hachem R et al (2016) A clinical practical approach to the surveillance definition of central line-associated bloodstream infection in cancer patients with mucosal barrier injury. Am J Infect Control 44:931-934. https://doi.org/10.1016/j. ajic.2016.03.011

23. Freeman JT, Elinder-Camburn A, McClymont C et al (2013) Central line-associated bloodstream infections in adult hematology patients with febrile neutropenia an evaluation of surveillance definitions using differential time to blood culture positivity. Infect Control Hosp Epidemiol 34:89-92. https://doi.org/10. 1086/668431

24. Metzger KE, Rucker Y, Callaghan M et al (2015) The burden of mucosal barrier injury laboratory-confirmed bloodstream infection among hematology, oncology, and stem cell transplant patients. Infect Control Hosp Epidemiol 36:119-124. https://doi.org/ 10.1017/ice.2014.38

25. O'Grady NP, Alexander M, Burns LA et al (2011) Guidelines for the prevention of intravascular catheter-related infections. Clin Infect Dis:52. https://doi.org/10.1093/cid/cir257

26. de Grooth HJ, Timsit JF, Mermel L et al (2020) Validity of surrogate endpoints assessing central venous catheter-related infection: evidence from individual- and study-level analyses. Clin Microbiol Infect 26:563-571. https://doi.org/10.1016/j.cmi.2019. 09.022

27. Robert K für K und I (KRINKO) beim, Koch-Institut R (2017) Prevention of vascular catheter-related infections: part 1nontunneled central venous catheters: recommendation of the Commission for Hospital Hygiene and Infection Prevention (KRINKO) at the Robert Koch Institute

28. Steinberg JP, Coffin SE (2013) Improving the central lineassociated bloodstream infection surveillance definition: a work in progress. Infect Control Hosp Epidemiol 34:777-779. https:// doi.org/10.1086/671369

29. Epstein L, See I, Edwards JR et al (2016) Mucosal barrier injury laboratory-confirmed bloodstream infections (MBI-LCBI): descriptive analysis of data reported to national healthcare safety network (NHSN), 2013. Infect Control Hosp Epidemiol 37:2-7. https://doi.org/10.1017/ice.2015.245

30. Kato Y, Hagihara M, Kurumiya A et al (2018) Impact of mucosal barrier injury laboratory-confirmed bloodstream infection (MBILCBI) on central line-associated bloodstream infections (CLABSIs) in department of hematology at single university hospital in Japan. J Infect Chemother 24:31-35. https://doi.org/10. 1016/j.jiac.2017.08.013

31. Biehl LM, Huth A, Panse J et al (2016) A randomized trial on chlorhexidine dressings for the prevention of catheter-related bloodstream infections in neutropenic patients. Ann Oncol 27: 1916-1922. https://doi.org/10.1093/annonc/mdw275
32. Schalk E, Teschner D, Hentrich M et al (2019) Central venous catheter-related bloodstream infections in patients with hematological malignancies: comparison of data from a clinical registry and a randomized controlled trial. Infect Control Hosp Epidemiol 41:254-256. https://doi.org/10.1017/ice.2019.335

33. Schalk E, Biehl LM, Färber J et al (2017) Determination of a cutoff time point for prophylactic exchange of central venous catheters for prevention of central venous catheter-related bloodstream infections in patients with hematological malignancies. Infect Control Hosp Epidemiol 38:888-889. https://doi.org/10. 1017/ice.2017.65

34. Schalk E, Vehreschild MJGT, Biehl LM (2020) Influence of different definitions of central venous catheter-related bloodstream infections on epidemiological parameters in cancer patients. 1-2. https://doi.org/10.1017/ice.2020.274

35. Linares J (2007) Diagnosis of catheter-related bloodstream infection: conservative techniques. Clin Infect Dis 44:827-829. https:// doi.org/10.1086/511885

36. Safdar N, Maki DG (2004) The pathogenesis of catheter-related bloodstream infection with noncuffed short-term central venous catheters. Intensive Care Med 30:62-67. https://doi.org/10.1007/ s00134-003-2045-Z

37. Luft D, Schmoor C, Wilson C et al (2010) Central venous catheter-associated bloodstream infection and colonisation of insertion site and catheter tip. What are the rates and risk factors in haematology patients? Ann Hematol 89:1265-1275. https://doi. org/10.1007/s00277-010-1005-2

38. Raad I (1998) Intravascular-catheter-related infections. Lancet 351:6-6

39. Dube WC, Jacob JT, Zheng Z et al (2020) Comparison of rates of central line-associated bloodstream infections in patients with $1 \mathrm{vs}$ 2 central venous catheters. JAMA Netw Open 3:e200396. https:// doi.org/10.1001/jamanetworkopen.2020.0396

40. Peris A, Zagli G, Bonizzoli M et al (2010) Implantation of 3951 long-term central venous catheters: performances, risk analysis, and patient comfort after ultrasound-guidance introduction. Anesth Analg 111:1194-1201. https://doi.org/10.1213/ANE. 0b013e3181f333c1

41. Mollee P, Jones M, Stackelroth J et al (2011) Catheter-associated bloodstream infection incidence and risk factors in adults with cancer: a prospective cohort study. J Hosp Infect 78:26-30. https://doi.org/10.1016/j.jhin.2011.01.018

42. Touré A, Vanhems P, Lombard-Bohas C et al (2012) Totally implantable central venous access port infections in patients with digestive cancer: incidence and risk factors. Am J Infect Control 40:935-939. https://doi.org/10.1016/j.ajic.2012.01.024

43. Howell PB, Walters PE, Donowitz GR, Farr BM (1995) Risk factors for infection of adult patients with cancer who have tunnelled central venous catheters. Cancer 75:1367-1375. https://doi.org/10.1002/1097-0142(19950315)75:6<1367::AIDCNCR2820750620>3.0.CO;2-Z

44. Wisplinghoff H, Seifert H, Wenzel RP, Edmond MB (2003) Current trends in the epidemiology of nosocomial bloodstream infections in patients with hematological malignancies and solid neoplasms in hospitals in the United States. Clin Infect Dis 36: 1103-1110. https://doi.org/10.1086/374339

45. Kochanek M, Schalk E, von Bergwelt-Baildon M et al (2019) Management of sepsis in neutropenic cancer patients: 2018 guidelines from the Infectious Diseases Working Party (AGIHO) and Intensive Care Working Party (iCHOP) of the German Society of Hematology and Medical Oncology (DGHO). Ann Hematol 98: 1051-1069. https://doi.org/10.1007/s00277-019-03622-0

46. Kiehl MG, Beutel G, Böll B et al (2018) Consensus statement for cancer patients requiring intensive care support. Ann Hematol 97: 1271-1282. https://doi.org/10.1007/s00277-018-3312-y 
47. Tölle D, Hentrich M, Pelzer BW et al (2019) Impact of neutropenia on central venous catheter-related bloodstream infections in patients with hematological malignancies at the time of central venous catheter insertion: a matched-pair analysis. Infect Control Hosp Epidemiol 40:1204-1206. https://doi.org/10.1017/ice.2019. 224

48. McDonald MK, Culos KA, Gatwood KS et al (2018) Defining incidence and risk factors for catheter-associated bloodstream infections in an outpatient adult hematopoietic cell transplantation program. Biol Blood Marrow Transplant 24:2081-2087. https:// doi.org/10.1016/j.bbmt.2018.04.031

49. Richters A, Van Vliet M, Peer PGM et al (2014) Incidence of and risk factors for persistent gram-positive bacteraemia and catheterrelated thrombosis in haematopoietic stem cell transplantation. Bone Marrow Transplant 49:264-269. https://doi.org/10.1038/ bmt.2013.172

50. Lordick F, Hentrich M, Decker T et al (2003) Ultrasound screening for internal jugular vein thrombosis aids the detection of central venous catheter-related infections in patients with haematooncological diseases: a prospective observational study. Br J Haematol 120:1073-1078. https://doi.org/10.1046/j.1365-2141. 2003.04199.x

51. Raad II, Luna M, Khalil SAM et al (1994) The relationship between the thrombotic and infectious complications of central venous catheters. JAMA J Am Med Assoc 271:1014-1016. https:// doi.org/10.1001/jama.1994.03510370066034

52. Meyer E, Beyersmann J, Bertz H et al (2007) Risk factor analysis of blood stream infection and pneumonia in neutropenic patients after peripheral blood stem-cell transplantation. Bone Marrow Transplant 39:173-178. https://doi.org/10.1038/sj.bmt.1705561

53. Lipitz-Snyderman A, Sepkowitz KA, Elkin EB et al (2014) Longterm central venous catheter use and risk of infection in older adults with cancer. J Clin Oncol. https://doi.org/10.1200/JCO. 2013.53.3018

54. Fang S, Yang J, Song L et al (2017) Comparison of three types of central venous catheters in patients with malignant tumor receiving chemotherapy. Patient Prefer Adherence 11:1197-1204. https://doi.org/10.2147/PPA.S142556

55. Groeger JS, Lucas AB, Thaler HT et al (1993) Infectious morbidity associated with long-term use of venous access devices in patients with cancer. Ann Intern Med 119:1168-1174. https:// doi.org/10.7326/0003-4819-119-12-199312150-00003

56. Patel GS, Jain K, Kumar R et al (2014) Comparison of peripherally inserted central venous catheters (PICC) versus subcutaneously implanted port-chamber catheters by complication and cost for patients receiving chemotherapy for non-haematological malignancies. Support Care Cancer 22:121-128. https://doi.org/10. 1007/s00520-013-1941-1

57. Cotogni P, Barbero C, Garrino C et al (2015) Peripherally inserted central catheters in non-hospitalized cancer patients: 5 -year results of a prospective study. Support Care Cancer 23:403-409. https:// doi.org/10.1007/s00520-014-2387-9

58. Chopra V, O'Horo JC, Rogers MAM et al (2013) The risk of bloodstream infection associated with peripherally inserted central catheters compared with central venous catheters in adults: a systematic review and meta-analysis. Infect Control Hosp Epidemiol 34:908-918. https://doi.org/10.1086/671737

59. Bellesi S, Chiusolo P, De Pascale G et al (2013) Peripherally inserted central catheters (PICCs) in the management of oncohematological patients submitted to autologous stem cell transplantation. Support Care Cancer 21:531-535. https://doi. org/10.1007/s00520-012-1554-0

60. Kang J, Chen W, Sun W et al (2017) Peripherally inserted central catheter-related complications in cancer patients: a prospective study of over 50,000 catheter days. J Vasc Access 18:153-157. https://doi.org/10.5301/jva.5000670
61. Lee JH, Kim ET, Shim DJ et al (2019) Prevalence and predictors of peripherally inserted central catheter-associated bloodstream infections in adults: a multicenter cohort study. PLoS One 14:19. https://doi.org/10.1371/journal.pone.0213555

62. Campagna S, Gonella S, Berchialla P et al (2019) Can peripherally inserted central catheters be safely placed in patients with cancer receiving chemotherapy? A retrospective study of almost 400,000 catheter-days. Oncologist:24. https://doi.org/10.1634/ theoncologist.2018-0281

63. Mariggiò E, Iori AP, Micozzi A et al (2020) Peripherally inserted central catheters in allogeneic hematopoietic stem cell transplant recipients. Support Care Cancer. https://doi.org/10.1007/s00520019-05269-z

64. McBride KD, Fisher R, Warnock N et al (1997) A comparative analysis of radiological and surgical placement of central venous catheters. Cardiovasc Intervent Radiol 20:17-22. https://doi.org/ 10.1007/s002709900103

65. Tomlinson D, Mermel LA, Ethier MC et al (2011) Defining bloodstream infections related to central venous catheters in patients with cancer: a systematic review. Clin Infect Dis 53:697710. https://doi.org/10.1093/cid/cir523

66. Sotir MJ, Lewis C, Bisher EW et al (1999) Epidemiology of device-associated infections related to a long-term implantable vascular access device. Infect Control Hosp Epidemiol 20:187191. https://doi.org/10.1086/501609

67. Worth LJ, Black J, Seymour JF et al (2008) Surveillance for catheter-associated bloodstream infection in hematology units: quantifying the characteristics of a practical case definition. Infect Control Hosp Epidemiol 29:358-360. https://doi.org/10. $1086 / 528879$

68. DiGiorgio MJ, Fatica C, Oden M et al (2012) Development of a modified surveillance definition of central line-associated bloodstream infections for patients with hematologic malignancies. Infect Control Hosp Epidemiol 33:865-868. https://doi.org/10. $1086 / 667380$

69. Dettenkofer M, Wilson C, Gratwohl A et al (2010) Skin disinfection with octenidine dihydrochloride for central venous catheter site care: a double-blind, randomized, controlled trial. Clin Microbiol Infect 16:600-606. https://doi.org/10.1111/j.14690691.2009.02917.x

70. Gudiol C, Garcia-Vidal C, Arnan M et al (2014) Etiology, clinical features and outcomes of pre-engraftment and post-engraftment bloodstream infection in hematopoietic SCT recipients. Bone Marrow Transplant 49:824-830. https://doi.org/10.1038/bmt. 2014.37

71. Chaberny IF, Ruseva E, Sohr D et al (2009) Surveillance with successful reduction of central line-associated bloodstream infections among neutropenic patients with hematologic or oncologic malignancies. Ann Hematol 88:907-912. https://doi.org/10.1007/ s00277-008-0687-1

72. Dettenkofer M, Wenzler-Rottele S, Babikir R et al (2005) Surveillance of nosocomial sepsis and pneumonia in patients with a bone marrow or peripheral blood stem cell transplant: a multicenter project. Clin Infect Dis 40:926-931. https://doi.org/10. $1086 / 428046$

73. German Reference Center for Surveillance of Nosocomial Infections. ONKO-KISS Module

74. Seifert H, Cornely O (2003) Cancer patients related to short-term nontunnelled catheters determined by quantitative blood cultures, differential time to positivity, and molecular epidemiological. J Clin Densitom ... 41:118-123. https://doi.org/10.1128/JCM.41. 1.118

75. Hummel M, Warga C, Hof $\mathrm{H}$ et al (2009) Diagnostic yield of blood cultures from antibiotic-nave and antibiotically treated patients with haematological malignancies and high-risk 
neutropenia. Scand J Infect Dis 41:650-655. https://doi.org/10. 1080/00365540903062150

76. Wisplinghoff $\mathrm{H}, \mathrm{Bischoff} \mathrm{T}$, Tallent SM, et al (2004) Cases from a prospective nationwide surveillance study. BSI US Hosp CID 309:179

77. Marcos M, Soriano A, Iñurrieta A et al (2011) Changing epidemiology of central venous catheter-related bloodstream infections: increasing prevalence of Gram-negative pathogens. J Antimicrob Chemother 66:2119-2125. https://doi.org/10.1093/jac/dkr231

78. Braun E, Hussein K, Geffen Y et al (2014) Predominance of Gram-negative bacilli among patients with catheter-related bloodstream infections. Clin Microbiol Infect 20:O627-O629. https:// doi.org/10.1111/1469-0691.12565

79. Chaftari AM, Hachem R, Jiang Y et al (2018) Changing epidemiology of catheter-related bloodstream infections in cancer patients. Infect Control Hosp Epidemiol 39:727-729. https://doi.org/10. 1017/ice. 2018.75

80. Dutcher K, Lederman ER, Brodine S, Patel S (2013) Impact of the 2013 revised Centers for Disease Control and Prevention central line-associated bloodstream infection (CLABSI) surveillance definition on inpatient hospital CLABSI rates: is it enough? Infect Control Hosp Epidemiol 34:999-1001. https://doi.org/10.1086/ 671739

81. Schmidt-Hieber M, Bierwirth J, Buchheidt D et al (2018) Diagnosis and management of gastrointestinal complications in adult cancer patients: 2017 updated evidence-based guidelines of the Infectious Diseases Working Party (AGIHO) of the German Society of Hematology and Medical Oncology (DGHO). Ann Hematol 97:31-49. https://doi.org/10.1007/ s00277-017-3183-7

82. Gudiol C, Bodro M, Simonetti A et al (2013) Changing aetiology, clinical features, antimicrobial resistance, and outcomes of bloodstream infection in neutropenic cancer patients. Clin Microbiol Infect 19:474-479. https://doi.org/10.1111/j.1469-0691.2012. 03879.x

83. Gustinetti G, Mikulska M (2016) Bloodstream infections in neutropenic cancer patients: a practical update. Virulence 7:280-297. https://doi.org/10.1080/21505594.2016.1156821

84. Montassier E, Batard E, Gastinne T et al (2013) Recent changes in bacteremia in patients with cancer: a systematic review of epidemiology and antibiotic resistance. Eur J Clin Microbiol Infect Dis 32:841-850. https://doi.org/10.1007/s10096-013-1819-7

85. Cairo J, Hachem R, Rangaraj G et al (2011) Predictors of catheterrelated gram-negative bacilli bacteraemia among cancer patients. Clin Microbiol Infect 17:1711-1716. https://doi.org/10.1111/j. 1469-0691.2011.03504.x

86. Coyle VM, McMullan R, Morris TCM et al (2004) Catheterrelated bloodstream infection in adult haematology patients: catheter removal practice and outcome. J Hosp Infect 57:325-331. https://doi.org/10.1016/j.jhin.2004.04.007

87. Heinz WJ, Buchheidt D, Christopeit M et al (2017) Diagnosis and empirical treatment of fever of unknown origin (FUO) in adult neutropenic patients: guidelines of the Infectious Diseases Working Party (AGIHO) of the German Society of Hematology and Medical Oncology (DGHO). Ann Hematol 96:1775-1792. https://doi.org/10.1007/s00277-017-3098-3

88. Bouza E, Alvarado N, Alcala L et al (2007) A randomized and prospective study of 3 procedures for the diagnosis of catheterrelated bloodstream infection without catheter withdrawal. Clin Infect Dis 44:820-826. https://doi.org/10.1086/511865

89. DesJardin JA, Falagas ME, Ruthazer R et al (1999) Clinical utility of blood cultures drawn from indwelling central venous catheters in hospitalized patients with cancer. Ann Intern Med 131:641647. https://doi.org/10.7326/AWED202001070

90. Guembe M, Rodríguez-Créixems M, Sánchez-Carrillo $\mathrm{C}$ et al (2012) Differential time to positivity (DTTP) for the diagnosis of catheter-related bloodstream infection: do we need to obtain one or more peripheral vein blood cultures? Eur J Clin Microbiol Infect Dis 31:1367-1372. https://doi.org/10.1007/s10096-0111451-3

91. Dobbins BM, Catton JA, Kite P et al (2003) Each lumen is a potential source of central venous catheter-related bloodstream infection. Crit Care Med 31:1688-1690. https://doi.org/10.1097/ 01.CCM.0000063257.04633.AE

92. Catton JA, Dobbins BM, Kite P et al (2005) In situ diagnosis of intravascular catheter-related bloodstream infection: a comparison of quantitative culture, differential time to positivity, and endoluminal brushing. Crit Care Med 33:787-791. https://doi. org/10.1097/01.CCM.0000157968.98476.F3

93. Krause R, Valentin T, Salzer H et al (2013) Which lumen is the source of catheter-related bloodstream infection in patients with multi-lumen central venous catheters? Infection 41:49-52. https:// doi.org/10.1007/s15010-012-0391-x

94. Planes AM, Calleja R, Bernet A et al (2016) Evaluación de la utilidad del hemocultivo cuantitativo en el diagnóstico de la bacteriemia relacionada con catéter: análisis comparativo de dos periodos (2002 y 2012). Enferm Infecc Microbiol Clin 34:484 489. https://doi.org/10.1016/j.eimc.2015.11.007

95. Blot F, Nitenberg GE, Chachaty E et al (1999) Diagnosis of catheter-related bacteraemia: a prospective comparison of the time to positivity of hub-blood versus peripheral-blood cultures. Lancet 354:1071-1077. https://doi.org/10.1016/S0140-6736(98)11134-0

96. Raad I, Hanna HA, Alakech B et al (2004) Differential time to positivity: a useful method for diagnosing catheter-related bloodstream infections. Ann Intern Med. https://doi.org/10.7326/00034819-140-1-200401060-00007

97. Abdelkefi A, Achour W, Ben Othman T et al (2005) Difference in time to positivity is useful for the diagnosis of catheter-related bloodstream infection in hematopoietic stem cell transplant recipients. Bone Marrow Transplant 35:397-401. https://doi.org/10. 1038/sj.bmt. 1704773

98. Rijnders BJA, Van Wijngaerden E, Peetermans WE (2002) Catheter-tip colonization as a surrogate end point in clinical studies on catheter-related bloodstream infection: how strong is the evidence? Clin Infect Dis 35:1053-1058. https://doi.org/10. 1086/342905

99. Rijnders BJA (2007) Diagnosing catheter-related bloodstream infection without catheter removal? Not so fast! Clin Infect Dis 45: 138

100. Guembe M, Martín-Rabadán P, Echenagusia A et al (2013) Value of superficial cultures for prediction of catheter-related bloodstream infection in long-term catheters: a prospective study. J Clin Microbiol 51:3025-3030. https://doi.org/10.1128/JCM. 01351-13

101. Eggimann P, Harbarth S, Constantin MN et al (2000) Impact of a prevention strategy targeted at vascular-access care on incidence of infections acquired in intensive care. Lancet 355:1864-1868. https://doi.org/10.1016/S0140-6736(00)02291-1

102. Pronovost P, Needham D, Berenholtz S et al (2006) An intervention to decrease catheter-related bloodstream infections in the ICU. N Engl J Med. https://doi.org/10.1056/NEJMoa061115

103. Pronovost PJ, Goeschel CA, Colantuoni E et al (2010) Sustaining reductions in catheter related bloodstream infections in Michigan intensive care units: observational study. BMJ 340:462. https:// doi.org/10.1136/bmj.c309

104. Guerin K, Wagner J, Rains K, Bessesen M (2010) Reduction in central line-associated bloodstream infections by implementation of a postinsertion care bundle. Am J Infect Control 38:430-433. https://doi.org/10.1016/j.ajic.2010.03.007

105. Peredo R, Sabatier C, Villagrá A et al (2010) Reduction in catheter-related bloodstream infections in critically ill patients through a multiple system intervention. Eur J Clin Microbiol 
Infect Dis 29:1173-1177. https://doi.org/10.1007/s10096-0100971-6

106. Ista E, van der Hoven B, Kornelisse RF et al (2016) Effectiveness of insertion and maintenance bundles to prevent central-lineassociated bloodstream infections in critically ill patients of all ages: a systematic review and meta-analysis. Lancet Infect Dis 16:724-734. https://doi.org/10.1016/S1473-3099(15)00409-0

107. Blot K, Bergs J, Vogelaers D et al (2014) Prevention of central line-associated bloodstream infections through quality improvement interventions: a systematic review and meta-analysis. Clin Infect Dis 59:96-105. https://doi.org/10.1093/cid/ciu239

108. Hugonnet S, Harbarth S, Sax H et al (2004) Nursing resources: a major determinant of nosocomial infection? Curr Opin Infect Dis 17:329-333. https://doi.org/10.1097/01.qco.0000136931.83167. d2

109. Needleman J, Buerhaus P, Mattke S et al (2002) Nurse-staffing levels and the quality of care in hospitals. N Engl J Med 346: 1715-1722. https://doi.org/10.1056/NEJMsa012247

110. Chaftari P, Chaftari AM, Adachi J et al (2017) Improvement in the diagnosis of catheter-related bloodstream infections in a tertiary cancer center. Am J Infect Control 45:e34-e39. https://doi.org/10. 1016/j.ajic.2016.12.009

111. Higuera F, Rosenthal VD, Duarte P et al (2005) The effect of process control on the incidence of central venous catheterassociated bloodstream infections and mortality in intensive care units in Mexico. Crit Care Med 33:2022-2027. https://doi.org/10. 1097/01.CCM.0000178190.89663.E5

112. Choi SW, Chang L, Hanauer DA et al (2013) Rapid reduction of central line infections in hospitalized pediatric oncology patients through simple quality improvement methods. Pediatr Blood Cancer 60:262-269. https://doi.org/10.1002/pbc.24187

113. Ibrahim KY, Pierrotti LC, Freire MP et al (2013) Health careassociated infections in hematology-oncology patients with neutropenia: a method of surveillance. Am J Infect Control 41:11311133. https://doi.org/10.1016/j.ajic.2013.03.299

114. Colombier MA, Lafaurie M, de Fontbrune FS et al (2016) Usefulness of daily surveillance blood cultures in allogeneic hematopoietic stem cell transplant recipients on steroids: a 1-year prospective study. Transpl Infect Dis 18:504-511. https://doi.org/ 10.1111/tid.12552

115. Ghazal SS, Stevens MP, Bearman GM, Edmond MB (2014) Utility of surveillance blood cultures in patients undergoing hematopoietic stem cell transplantation. Antimicrob Resist Infect Control 3:1-5. https://doi.org/10.1186/2047-2994-3-20

116. Kameda K, Kimura S, Akahoshi Y et al (2016) High incidence of afebrile bloodstream infection detected by surveillance blood culture in patients on corticosteroid therapy after allogeneic hematopoietic stem cell transplantation. Biol Blood Marrow Transplant 22:371-377. https://doi.org/10.1016/j.bbmt.2015.09.019

117. Stohs E, Chow VA, Liu C et al (2019) Limited utility of outpatient surveillance blood cultures in hematopoietic cell transplant recipients on high-dose steroids for treatment of acute graft-versushost-disease. Biol Blood Marrow Transplant 25:1247-1252. https://doi.org/10.1016/j.bbmt.2019.01.031

118. Raad II, Hohn DC, Gilbreath BJ et al (1994) Prevention of central venous catheter-related infections by using maximal sterile barrier precautions during insertion. Infect Control Hosp Epidemiol. https://doi.org/10.2307/30145574

119. Cavanna L, Citterio C, Di Nunzio C et al (2020) Central venous catheterization in cancer patients with severe thrombocytopenia: ultrasound-guide improves safety avoiding prophylactic platelet transfusion. Mol Clin Oncol 12:435-439. https://doi.org/10. 3892/mco.2020.2010

120. Brass P, Hellmich M, Kolodziej L et al (2015) Ultrasound guidance versus anatomical landmarks for internal jugular vein catheterization SUMMARY OF FINDINGS FOR THE MAIN
COMPARISON. Cochrane Database Syst Rev:CD006962. https://doi.org/10.1002/14651858.CD006962.pub2.www. cochranelibrary.com

121. Brass P, Hellmich M, Kolodziej L et al (2015) Ultrasound guidance versus anatomical landmarks for subclavian or femoral vein catheterization SO-: Cochrane Database of Systematic Reviews YR-: 2015 NO-: 1. Cochrane Database Syst Rev. https://doi.org/ 10.1002/14651858.CD011447.www.cochranelibrary.com

122. Imataki O, Shimatani M, Ohue Y, Uemura M (2019) Effect of ultrasound-guided central venous catheter insertion on the incidence of catheter-related bloodstream infections and mechanical complications. BMC Infect Dis 19:1-7. https://doi.org/10.1186/ s12879-019-4487-0

123. Hewlett AL, Rupp ME (2012) New developments in the prevention of intravascular catheter associated infections. Infect Dis Clin $\mathrm{N}$ Am

124. Maki DG, Alvarado CJ, Ringer M (1991) Prospective randomised trial of povidone-iodine, alcohol, and chlorhexidine for prevention of infection associated with central venous and arterial catheters. Lancet. https://doi.org/10.1016/0140-6736(91)90479-9

125. Raad I, Hanna H, Maki D (2007) Intravascular catheter-related infections: advances in diagnosis, prevention, and management. Lancet Infect Dis 7:645-657. https://doi.org/10.1016/S14733099(07)70235-9

126. Lai NM, Lai NA, O’Riordan E et al (2016) Skin antisepsis for reducing central venous catheter-related infections. Cochrane Database Syst Rev

127. Hainsworth JD, Rubin MS, Spigel DR et al (2013) Molecular gene expression profiling to predict the tissue of origin and direct sitespecific therapy in patients with carcinoma of unknown primary site: a prospective trial of the Sarah Cannon Research Institute. J Clin Oncol 31:217-223. https://doi.org/10.1200/JCO.2012.43. 3755

128. Chaiyakunapruk N, Veenstra DL, Lipsky BA, Saint S (2002) Chlorhexidine compared with povidone-iodine solution for vascular catheter-site care: a meta-analysis. Ann Intern Med. https:// doi.org/10.7326/0003-4819-136-11-200206040-00007

129. Girard R, Comby C, Jacques D (2012) Alcoholic povidone-iodine or chlorhexidine-based antiseptic for the prevention of central venous catheter-related infections: in-use comparison. J Infect Public Health 5:35-42. https://doi.org/10.1016/j.jiph.2011.10.007

130. Mimoz O, Lucet J-C, Kerforne T et al (2015) Chlorhexidinealcohol versus povidone iodine-alcohol antisepsis for catheterrelated infection prevention: an open-label, multicentre, randomised controlled trial. Intensive Care Med Exp 3:A409. https://doi.org/10.1186/2197-425x-3-s1-a409

131. Ohtake S, Takahashi H, Nakagawa M et al (2018) One percent chlorhexidine-alcohol for preventing central venous catheterrelated infection during intensive chemotherapy for patients with haematologic malignancies. J Infect Chemother 24:544-548. https://doi.org/10.1016/j.jiac.2018.03.001

132. Mermel LA (2020) Sequential use of povidone-iodine and chlorhexidine for cutaneous antisepsis: a systematic review. Infect Control Hosp Epidemiol 41:98-101. https://doi.org/10.1017/ice. 2019.287

133. Tietz A, Frei R, Dangel M et al (2005) Octenidine hydrochloride for the care of central venous catheter insertion sites in severely immunocompromised patients. Infect Control Hosp Epidemiol. https://doi.org/10.1086/502606

134. Langgartner J, Linde HJ, Lehn $\mathrm{N}$ et al (2004) Combined skin disinfection with chlorhexidine/propanol and aqueous povidoneiodine reduces bacterial colonisation of central venous catheters. Intensive Care Med 30:1081-1088. https://doi.org/10.1007/ s00134-004-2282-9 
135. Climo MW, Yokoe DS, Warren DK et al (2013) Effect of daily chlorhexidine bathing on hospital-acquired infection. N Engl J Med 368:533-542. https://doi.org/10.1056/NEJMoa1113849

136. Frost SA, Alogso MC, Metcalfe L et al (2016) Chlorhexidine bathing and health care-associated infections among adult intensive care patients: a systematic review and meta-analysis. Crit Care 20:16-21. https://doi.org/10.1186/s13054-016-1553-5

137. Cobb DK, High KP, Sawyer RG et al (1992) A controlled trial of scheduled replacement of central venous and pulmonary-artery catheters. N Engl J Med. https://doi.org/10.1056/ NEJM199210083271505

138. Cook D, Randolph A, Kernerman P et al (1997) Central venous catheter replacement strategies: a systematic review of the literature. Crit Care Med. https://doi.org/10.1097/00003246199708000-00033

139. Ullman AJ, Cooke ML, Gillies D et al (2013) Optimal timing for intravascular administration set replacement. Cochrane Database Syst Rev 2013. https://doi.org/10.1002/14651858.CD003588. pub3

140. Rasero L, Degl'Innocenti M, Mocali M et al (2000) Comparison of two different time interval protocols for central venous catheter dressing in bone marrow transplant patients: results of a randomized, multicenter study. Haematologica

141. Ullman AJ, Cooke ML, Mitchell M et al (2015) Dressings and securement devices for central venous catheters (CVC). Cochrane Database Syst Rev

142. Dang FP, Li HJ, Tian JH (2019) Comparative efficacy of 13 antimicrobial dressings and different securement devices in reducing catheter-related bloodstream infections: a Bayesian network metaanalysis. Medicine (Baltimore) 98:e14940. https://doi.org/10. 1097/MD.0000000000014940

143. de Campos Pereira Silveira RC, dos Reis PED, Ferreira EB et al (2020) Dressings for the central venous catheter to prevent infection in patients undergoing hematopoietic stem cell transplantation: a systematic review and meta-analysis. Support Care Cancer 28:425-438. https://doi.org/10.1007/s00520-019-05065-9

144. Ruschulte H, Franke M, Gastmeier P et al (2009) Prevention of central venous catheter related infections with chlorhexidine gluconate impregnated wound dressings: a randomized controlled trial. Ann Hematol 88:267-272. https://doi.org/10.1007/s00277008-0568-7

145. Timsit JF, Schwebel C, Bouadma L et al (2009) Chlorhexidineimpregnated sponges and less frequent dressing changes for prevention of catheter-related infections in critically III adults: a randomized controlled trial. JAMA - J Am Med Assoc. https://doi. org/10.1001/jama.2009.376

146. Timsit JF, Mimoz O, Mourvillier B et al (2012) Randomized controlled trial of chlorhexidine dressing and highly adhesive dressing for preventing catheter-related infections in critically ill adults. Am J Respir Crit Care Med 186:1272-1278. https://doi. org/10.1164/rccm.201206-1038OC

147. Eggimann P, Pagani JL, Dupuis-Lozeron E et al (2019) Sustained reduction of catheter-associated bloodstream infections with enhancement of catheter bundle by chlorhexidine dressings over 11 years. Intensive Care Med 45:823-833. https://doi.org/10.1007/ s00134-019-05617-x

148. Wei L, Li Y, Li X et al (2019) Chlorhexidine-impregnated dressing for the prophylaxis of central venous catheter-related complications: a systematic review and meta-analysis. BMC Infect Dis 19:1-12. https://doi.org/10.1186/s12879-019-4029-9

149. Kamboj M, Blair R, Bell N et al (2015) Use of disinfection cap to reduce central-line - associated bloodstream infection and blood culture contamination among hematology — oncology patients. Infect Control Hosp Epidemiol 36:1401-1408. https://doi.org/10. 1017/ice.2015.219
150. Patel PA, Boehm S, Zhou Y et al (2017) Prospective observational study on central line-associated bloodstream infections and central venous catheter occlusions using a negative displacement connector with an alcohol disinfecting cap. Am J Infect Control 45: 115-120. https://doi.org/10.1016/j.ajic.2016.06.013

151. Farkas JC, Liu N, Bleriot JP et al (1992) Single- versus triplelumen central catheter-related sepsis: a prospective randomized study in a critically ill population. Am J Med 93:277-282. https://doi.org/10.1016/0002-9343(92)90233-2

152. Ma TY, Yoshinaka R, Banaag A et al (1998) Total parenteral nutrition via multilumen catheters does not increase the risk of catheter-related sepsis: a randomized, prospective study. Clin Infect Dis 27:500-503. https://doi.org/10.1086/514687

153. Dezfulian C, Lavelle J, Nallamothu BK et al (2003) Rates of infection for single-lumen versus multilumen central venous catheters: a meta-analysis. Crit Care Med 31:2385-2390. https://doi. org/10.1097/01.CCM.0000084843.31852.01

154. Yamamoto AJ, Solomon JA, Soulen MC et al (2002) Sutureless securement device reduces complications of peripherally inserted central venous catheters. J Vasc Interv Radiol 13:77-81. https:// doi.org/10.1016/S1051-0443(07)60012-8

155. Goetz AM, Wagener MM, Miller JM, Muder RR (1998) Risk of infection due to central venous catheters: effect of site of placement and catheter type. Infect Control Hosp Epidemiol 19:842845. https://doi.org/10.2307/30141562

156. Merrer J, De Jonghe B, Golliot F et al (2001) Complications of femoral and subclavian venous catheterization in critically III patients: a randomized controlled trial. J Am Med Assoc. https://doi. org/10.1001/jama.286.6.700

157. Ge X, Cavallazzi R, Li C et al (2018) Central venous access sites for the prevention of venous thrombosis, stenosis and infection. Cochrane Database Syst Rev. https://doi.org/10.1002/14651858. CD004084.pub3

158. Mer M, Duse AG, Galpin JS, Richards GA (2009) Central venous catheterization: a prospective, randomized, double-blind study. Clin Appl Thromb. https://doi.org/10.1177/1076029608319878

159. Parienti JJ, Mongardon N, Mégarbane B et al (2015) Intravascular complications of central venous catheterization by insertion site. $\mathrm{N}$ Engl J Med 373:1220-1229. https://doi.org/10.1056/ NEJMoa1500964

160. Arvaniti K, Lathyris D, Blot S et al (2017) Cumulative evidence of randomized controlled and observational studies on catheterrelated infection risk of central venous catheter insertion site in ICU patients: a pairwise and network meta-analysis. Crit Care Med 45:e437-e448. https://doi.org/10.1097/CCM. 0000000000002092

161. Parienti JJ (2017) Catheter-related bloodstream infection in jugular versus subclavian central catheterization. Crit Care Med 45: e734-e735. https://doi.org/10.1097/CCM.0000000000002400

162. Heidenreich D, Hansen E, Kreil S et al (2020) Influence of the insertion site on central venous catheter-related complications in patients undergoing allogeneic hematopoietic cell transplantation. Biol Blood Marrow Transplant. https://doi.org/10.1016/j.bbmt. 2020.02.007

163. Lennon M, Zaw NN, Pöpping DM, Wenk M (2012) Procedural complications of central venous catheter insertion. Minerva Anestesiol 78:1234-1240

164. Björkander M, Bentzer P, Schött U et al (2019) Mechanical complications of central venous catheter insertions: a retrospective multicenter study of incidence and risks. Acta Anaesthesiol Scand 63:61-68. https://doi.org/10.1111/aas.13214

165. Veenstra DL, Saint S, Saha S et al (1999) Efficacy of antisepticimpregnated central venous catheters in preventing catheterrelated bloodstream infection: a meta-analysis. J Am Med Assoc

166. Ostendorf T, Meinhold A, Harter C et al (2005) Chlorhexidine and silver-sulfadiazine coated central venous catheters in 
haematological patients-a double-blind, randomised, prospective, controlled trial. Support Care Cancer 13:993-1000. https://doi. org/10.1007/s00520-005-0812-9

167. Chong HY, Lai NM, Apisarnthanarak A, Chaiyakunapruk N (2017) Comparative efficacy of antimicrobial central venous catheters in reducing catheter-related bloodstream infections in adults: abridged Cochrane systematic review and network meta-analysis. Clin Infect Dis 64:S131-S140. https://doi.org/10.1093/cid/cix019

168. Lai NM, Chaiyakunapruk N, Lai NA et al (2016) Catheter impregnation, coating or bonding for reducing central venous catheterrelated infections in adults. Cochrane Database Syst Rev 2016. https://doi.org/10.1002/14651858.CD007878.pub3

169. Jaeger K, Zenz S, Jüttner B et al (2005) Reduction of catheterrelated infections in neutropenic patients: a prospective controlled randomized trial using a chlorhexidine and silver sulfadiazineimpregnated central venous catheter. Ann Hematol 84:258-262. https://doi.org/10.1007/s00277-004-0972-6

170. Raad I, Darouiche R, Dupuis J et al (1997) Central venous catheters coated with minocycline and rifampin for the prevention of catheter-related colonization and bloodstream infections: a randomized, double-blind trial. Ann Intern Med 127:267-274. https://doi.org/10.7326/0003-4819-127-4-199708150-00002

171. Darouiche RO, Raad II, Heard SO et al (1999) A comparison of two antimicrobial-impregnated central venous catheters. N Engl J Med. https://doi.org/10.1056/NEJM199901073400101

172. Darouiche RO, Berger DH, Khardori N et al (2005) Comparison of antimicrobial impregnation with tunneling of long-term central venous catheters: a randomized controlled trial. Ann Surg 242: 193-200. https://doi.org/10.1097/01.sla.0000171874.29934.61

173. Hanna H, Benjamin R, Chatzinikolaou I et al (2004) Long-term silicone central venous catheters impregnated with minocycline and rifampin decrease rates of catheter-related bloodstream infection in cancer patients: a prospective randomized clinical trial. J Clin Oncol 22:3163-3171. https://doi.org/10.1200/JCO.2004.04. 124

174. Yücel N, Lefering R, Maegele M et al (2004) Reduced colonization and infection with miconazole-rifampicin modified central venous catheters: a randomized controlled clinical trial. J Antimicrob Chemother 54:1109-1115. https://doi.org/10.1093/ $\mathrm{jac} / \mathrm{dkh} 483$

175. León C, Ruiz-Santana S, Rello J et al (2004) Benefits of minocycline and rifampin-impregnated central venous catheters: a prospective, randomized, double-blind, controlled, multicenter trial. Intensive Care Med 30:1891-1899. https://doi.org/10.1007/ s00134-004-2378-2

176. Bonne S, Mazuski JE, Sona C et al (2015) Effectiveness of minocycline and rifampin vs chlorhexidine and silver sulfadiazine-impregnated central venous catheters in preventing central line-associated bloodstream infection in a high-volume academic intensive care unit: a before and after trial. J Am Coll Surg 221:739-747. https://doi.org/10.1016/j.jamcollsurg.2015. 05.013

177. Chemaly RF, Sharma PS, Youssef S et al (2010) The efficacy of catheters coated with minocycline and rifampin in the prevention of catheter-related bacteremia in cancer patients receiving highdose interleukin-2. Int J Infect Dis 14:e548-e552. https://doi.org/ 10.1016/j.jiid.2009.08.007

178. van de Wetering MD, van Woensel JBM, Lawrie TA (2016) Prophylactic antibiotics for preventing Gram positive infections associated with long-term central venous catheters in oncology patients (review). https://doi.org/10.1002/14651858.CD003295. pub3.www.cochranelibrary.com

179. Ziegler M, Landsburg D, Pegues D et al (2019) Fluoroquinolone prophylaxis is highly effective for the prevention of central lineassociated bloodstream infections in autologous stem cell transplant patients. Biol Blood Marrow Transplant 25:10041010. https://doi.org/10.1016/j.bbmt.2018.11.023

180. Zakrzewska-Bode A, Muytjens HL, Liem KD, HoogkampKorstanje JAA (1995) Mupirocin resistance in coagulasenegative staphylococci, after topical prophylaxis for the reduction of colonization of central venous catheters. J Hosp Infect 31:189 193. https://doi.org/10.1016/0195-6701(95)90065-9

181. Goossens GA, Jérôme M, Janssens C et al (2013) Comparing normal saline versus diluted heparin to lock non-valved totally implantable venous access devices in cancer patients: a randomised, non-inferiority, open trial. Ann Oncol 24:18921899. https://doi.org/10.1093/annonc/mdt1 14

182. Gudiol C, Arnan M, Aguilar-Guisado M et al (2020) A randomized, double-blind, placebo-controlled trial (TAURCAT study) of citrate lock solution for prevention of endoluminal central venous catheter infection in neutropenic hematological patients. Antimicrob Agents Chemother. https://doi.org/10.1128/AAC. 01521-19

183. Sanders J, Pithie A, Ganly P et al (2008) A prospective doubleblind randomized trial comparing intraluminal ethanol with heparinized saline for the prevention of catheter-associated bloodstream infection in immunosuppressed haematology patients. J Antimicrob Chemother 62:809-815. https://doi.org/10.1093/jac/ dkn284

184. Schoot RA, Van Ommen CH, Stijnen T et al (2015) Prevention of central venous catheter-associated bloodstream infections in paediatric oncology patients using 70\% ethanol locks: a randomised controlled multi-centre trial. Eur J Cancer 51:2031-2038. https:// doi.org/10.1016/j.ejca.2015.06.126

185. Slobbe L, Doorduijn JK, Lugtenburg PJ et al (2010) Prevention of catheter-related bacteremia with a daily ethanol lock in patients with tunnelled catheters: a randomized, placebo-controlled trial. PLoS One 5:1-8. https://doi.org/10.1371/journal.pone.0010840

186. Worth LJ, Slavin MA, Heath S et al (2014) Ethanol versus heparin locks for the prevention of central venous catheter-associated bloodstream infections: a randomized trial in adult haematology patients with Hickman devices. J Hosp Infect 88:48-51. https:// doi.org/10.1016/j.jhin.2014.06.007

187. Carratalà J, Niubó J, Fernández-Sevilla A et al (1999) Randomized, double-blind trial of an antibiotic-lock technique for prevention of gram-positive central venous catheter-related infection in neutropenic patients with cancer. Antimicrob Agents Chemother 43:2200-2204. https://doi.org/10.1128/aac. 43.9.2200

188. Safdar N, Maki DG (2006) Use of vancomycin-containing lock or flush solutions for prevention of bloodstream infection associated with central venous access devices: a meta-analysis of prospective, randomized trials. Clin Infect Dis 43:474-484. https://doi.org/10. 1086/505976

189. Zacharioudakis IM, Zervou FN, Arvanitis M et al (2014) Antimicrobial lock solutions as a method to prevent central lineassociated bloodstream infections: a meta-analysis of randomized controlled trials. Clin Infect Dis 59:1741-1749. https://doi.org/10. 1093/cid/ciu671

190. Bassetti M, Merelli M, Ansaldi F et al (2015) Clinical and therapeutic aspects of candidemia: a five year single centre study. PLoS One 10:1-12. https://doi.org/10.1371/journal.pone.0127534

191. Fares J, Khalil M, Chaftari AM et al (2019) Impact of catheter management on clinical outcome in adult cancer patients with Gram-negative bacteremia. Open Forum Infect Dis 6:1-6. https://doi.org/10.1093/ofid/ofz357

192. Kim EJ, Kim YC, Ahn JY et al (2019) Risk factors for mortality in patients with Stenotrophomonas maltophilia bacteremia and clinical impact of quinolone-resistant strains. BMC Infect Dis 19:1-8. https://doi.org/10.1186/s12879-019-4394-4 
193. Raad S, Chaftari AM, Hachem RY et al (2018) Removal and insertion of central venous catheters in cancer patients is associated with high symptom burden. Expert Rev Med Devices 15:591596. https://doi.org/10.1080/17434440.2018.1500892

194. Fowler VG, Sanders LL, Sexton DJ et al (1998) Outcome of Staphylococcus aureus bacteremia according to compliance with recommendations of infectious diseases specialists: experience with 244 patients. Clin Infect Dis 27:478-486. https://doi.org/10. 1086/514686

195. Fowler VG, Justice A, Moore C et al (2005) Risk factors for hematogenous complications of intravascular catheter-associated Staphylococcus aureus bacteremia. Clin Infect Dis 40:695-703. https://doi.org/10.1086/427806

196. Dugdale DC, Ramsey PG (1990) Staphylococcus aureus bacteremia in patients with Hickman catheters. Am J Med 89:137-141. https://doi.org/10.1016/0002-9343(90)90290-T

197. Kim S-H, Kang C-I, Kim H-B et al (2003) Outcomes of Hickman catheter salvage in febrile neutropenic cancer patients with Staphylococcus aureus bacteremia. Infect Control Hosp Epidemiol. https://doi.org/10.1086/502157

198. El Zakhem A, Chaftari AM, Bahu R et al (2014) Central lineassociated bloodstream infections caused by Staphylococcus aureus in cancer patients: clinical outcome and management. Ann Med 46:163-168. https://doi.org/10.3109/07853890.2013. 878513

199. Raad I, Hanna H, Boktour M et al (2004) Management of central venous catheters in patients with cancer and candidemia. Clin Infect Dis 38:1119-1127. https://doi.org/10.1086/382874

200. Nucci M, Anaissie E (2001) Revisiting the source of candidemia: skin or gut? Clin Infect Dis 33:1959-1967. https://doi.org/10. $1086 / 323759$

201. Nucci M, Silveira MI, Spector N et al (1998) Risk factors for death among cancer patients with fungemia. Clin Infect Dis 27:107-111. https://doi.org/10.1086/514609

202. Nucci M, Colombo AL, Silveira F et al (1998) Risk factors for death in patients with candidemia. Infect Control Hosp Epidemiol. https://doi.org/10.2307/30141563

203. Nucci M, Anaissie E, Betts RF et al (2010) Early removal of central venous catheter in patients with candidemia does not improve outcome: analysis of 842 patients from 2 randomized clinical trials. Clin Infect Dis 51:295-303. https://doi.org/10.1086/ 653935

204. Slavin MA, Sorrell TC, Marriott D et al (2010) Candidaemia in adult cancer patients: risks for fluconazole-resistant isolates and death. J Antimicrob Chemother 65:1042-1051. https://doi.org/10. 1093/jac/dkq053

205. Liu CY, Huang LJ, Wang WS et al (2009) Candidemia in cancer patients: impact of early removal of non-tunneled central venous catheters on outcome. J Inf Secur 58:154-160. https://doi.org/10. 1016/j.jinf.2008.12.008

206. Janum S, Afshari A (2016) Central venous catheter (CVC) removal for patients of all ages with candidaemia. Cochrane Database Syst Rev

207. Ruhnke M, Cornely OA, Schmidt-Hieber M et al (2020) Treatment of invasive fungal diseases in cancer patientsrevised 2019 recommendations of the Infectious Diseases Working Party (AGIHO) of the German Society of Hematology and Oncology (DGHO). Mycoses 63:653-682. https://doi.org/10. 1111/myc. 13082

208. Criscuolo M, Marchesi F, Candoni A et al (2019) Fungaemia in haematological malignancies: SEIFEM-2015 survey. Eur J Clin Investig 49:1-10. https://doi.org/10.1111/eci.13083

209. Lee YM, Moon C, Kim YJ, et al (2018) Clinical impact of delayed catheter removal for patients with central-venous-catheter-related Gram-negative bacteraemia. The Healthcare Infection Society
210. Friedman ND, Korman TM, Fairley CK et al (2002) Bacteraemia due to Stenotrophomonas maltophilia: an analysis of 45 episodes. J Inf Secur 45:47-53. https://doi.org/10.1053/jinf.2002.0978

211. Boktour M, Hanna H, Ansari S et al (2006) Central venous catheter and Stenotrophomonas maltophilia bacteremia in cancer patients. Cancer 106:1967-1973. https://doi.org/10.1002/cncr. 21846

212. Hebeisen UP, Atkinson A, Marschall J, Buetti N (2019) Catheterrelated bloodstream infections with coagulase-negative staphylococci: are antibiotics necessary if the catheter is removed? Antimicrob Resist Infect Control 8:1-8. https://doi.org/10.1186/ s13756-019-0474-x

213. Raad I, Kassar R, Ghannam D et al (2009) Management of the catheter in documented catheter-related coagulase-negative staphylococcal bacteremia: remove or retain? Clin Infect Dis 49:11871194. https://doi.org/10.1086/605694

214. Wang CC, Mattson D, Wald A (2001) Corynebacterium jeikeium bacteremia in bone marrow transplant patients with Hickman catheters. Bone Marrow Transplant 27:445-449. https://doi.org/10. 1038/sj.bmt. 1702808

215. Ghide S, Jiang Y, Hachem R et al (2010) Catheter-related Corynebacterium bacteremia: should the catheter be removed and vancomycin administered? Eur J Clin Microbiol Infect Dis 29:153-156. https://doi.org/10.1007/s10096-009-0827-0

216. Chaftari AM, El Zakhem A, Jamal MA et al (2014) The use of minocycline-rifampin coated central venous catheters for exchange of catheters in the setting of staphylococcus aureus central line associated bloodstream infections. BMC Infect Dis 14:1-5. https://doi.org/10.1186/1471-2334-14-518

217. Chaftari AM, Kassis C, El Issa H et al (2011) Novel approach using antimicrobial catheters to improve the management of central line-associated bloodstream infections in cancer patients. Cancer 117:2551-2558. https://doi.org/10.1002/cncr.25807

218. Cesaro S, Cavaliere M, Spiller M et al (2007) A simplified method of antibiotic lock therapy for Broviac-Hickman catheters using a CLC 2000 connector device. Support Care Cancer 15:95-99. https://doi.org/10.1007/s00520-006-0099-5

219. Funalleras G, Fernández-Hidalgo N, Borrego A et al (2011) Effectiveness of antibiotic-lock therapy for long-term catheter-related bacteremia due to gram-negative bacilli: a prospective observational study. Clin Infect Dis 53:129-132. https://doi.org/10. 1093/cid/cir551

220. Del Pozo JL, Cenoz MG, Hernáez S et al (2009) Effectiveness of teicoplanin versus vancomycin lock therapy in the treatment of port-related coagulase-negative staphylococci bacteraemia: a prospective case-series analysis. Int J Antimicrob Agents 34:482485. https://doi.org/10.1016/j.ijantimicag.2009.06.020

221. Norris LAB, Kablaoui F, Brilhart MK, Bookstaver PB (2017) Systematic review of antimicrobial lock therapy for prevention of central-line-associated bloodstream infections in adult and pediatric cancer patients. Int J Antimicrob Agents 50:308-317. https://doi.org/10.1016/j.ijantimicag.2017.06.013

222. Gominet M, Compain F, Beloin C, Lebeaux D (2017) Central venous catheters and biofilms: where do we stand in 2017 ? Apmis 125:365-375. https://doi.org/10.1111/apm.12665

223. Ahmad A, Moser C, Classen V et al (2019) Hydrochloric acid prolongs the lifetime of central venous catheters in haematologic patients with bacteraemia. Dan Med J 66:1-4

224. Wolf J, Connell TG, Allison KJ et al (2018) Treatment and secondary prophylaxis with ethanol lock therapy for central lineassociated bloodstream infection in paediatric cancer: a randomised, double-blind, controlled trial. Lancet Infect Dis 18: 854-863. https://doi.org/10.1016/S1473-3099(18)30224-X

225. Hachem R, Kanj S, Hamerschlak N et al (2018) International experience with minocycline, EDTA and ethanol lock for salvaging of central line associated bloodstream infections. Expert Rev 
Med Devices 15:461-466. https://doi.org/10.1080/17434440. 2018.1483237

226. O'Horo JC, Silva GLM, Safdar N (2011) Anti-infective locks for treatment of central line-associated bloodstream infection: a systematic review and meta-analysis. Am J Nephrol 34:415-422. https://doi.org/10.1159/000331262

227. Raad I, Chaftari AM, Zakhour R et al (2016) Successful salvage of central venous catheters in patients with catheter-related or central line-associated bloodstream infections by using a catheter lock solution consisting of minocycline, EDTA, and 25\% ethanol. Antimicrob Agents Chemother 60:3426-3432. https://doi.org/10. 1128/AAC.02565-15

228. Beyar-Katz O, Dickstein Y, Borok S et al (2017) Empirical antibiotics targeting gram-positive bacteria for the treatment of febrile neutropenic patients with cancer. Cochrane Database Syst Rev
229. Raad II, Sabbagh MF (1992) Optimal duration of therapy for catheter-related Staphylococcus aureus bacteremia: a study of 55 cases and review. Clin Infect Dis. https://doi.org/10.1093/clinids/ 14.1.75

230. Pigrau C, Rodríguez D, Planes AM et al (2003) Management of catheter-related Staphylococcus aureus bacteremia: when may sonographic study be unnecessary? Eur J Clin Microbiol Infect Dis 22:713-719. https://doi.org/10.1007/s10096-003-1041-0

231. Stern A, Carrara E, Bitterman R et al (2019) Early discontinuation of antibiotics for febrile neutropenia versus continuation until neutropenia resolution in people with cancer. Cochrane Database Syst Rev

Publisher's note Springer Nature remains neutral with regard to jurisdictional claims in published maps and institutional affiliations. 